\title{
MicroRNA Profiling Reveals Marker of Motor Neuron Disease in ALS Models
}

\author{
Mariah L. Hoye, ${ }^{1}$ Erica D. Koval, ${ }^{1}$ Amy J. Wegener, ${ }^{1}$ Theodore S. Hyman, ${ }^{1}$ Chengran Yang, ${ }^{2}$ David R. 0’Brien, ${ }^{2}$ \\ ORebecca L. Miller, ${ }^{1}$ Tracy Cole, ${ }^{3}$ Kathleen M. Schoch, ${ }^{1}$ Tao Shen, ${ }^{1}$ Tomonori Kunikata, ${ }^{1}$ Jean-Philippe Richard, ${ }^{4}$ \\ David H. Gutmann, ${ }^{1}$ Nicholas J. Maragakis, ${ }^{4}$ Holly B. Kordasiewicz, ${ }^{3}$ Joseph D. Dougherty, ${ }^{2}$ and Timothy M. Miller ${ }^{1}$ \\ ${ }^{1}$ Department of Neurology, ${ }^{2}$ Department of Genetics, and ${ }^{2}$ Department of Psychiatry, Washington University School of Medicine, St. Louis, Missouri 63110, \\ ${ }^{3}$ Ionis Pharmaceuticals, Carlsbad, California 92010, and ${ }^{4}$ Department of Neurology, Johns Hopkins University School of Medicine, Baltimore, Maryland
} 21205

Amyotrophic lateral sclerosis (ALS) is a progressive neurodegenerative disorder marked by the loss of motor neurons (MNs) in the brain and spinal cord, leading to fatally debilitating weakness. Because this disease predominantly affects MNs, we aimed to characterize the distinct expression profile of that cell type to elucidate underlying disease mechanisms and to identify novel targets that inform on MN health during ALS disease time course. microRNAs (miRNAs) are short, noncoding RNAs that can shape the expression profile of a cell and thus often exhibit cell-type-enriched expression. To determine MN-enriched miRNA expression, we used Cre recombinasedependent miRNA tagging and affinity purification in mice. By defining the in vivo miRNA expression of MNs, all neurons, astrocytes, and microglia, we then focused on MN-enriched miRNAs via a comparative analysis and found that they may functionally distinguish MNs postnatally from other spinal neurons. Characterizing the levels of the MN-enriched miRNAs in CSF harvested from ALS models of MN disease demonstrated that one miRNA (miR-218) tracked with MN loss and was responsive to an ALS therapy in rodent models. Therefore, we have used cellular expression profiling tools to define the distinct miRNA expression of MNs, which is likely to enrich future studies of MN disease. This approach enabled the development of a novel, drug-responsive marker of MN disease in ALS rodents.

Key words: ALS; microRNAs; miRAP; motor neuron; motor neuron disease; TRAP

\section{Significance Statement}

Amyotrophic lateral sclerosis (ALS) is a neurodegenerative disease in which motor neurons (MNs) in the brain and spinal cord are selectively lost. To develop tools to aid in our understanding of the distinct expression profiles of MNs and, ultimately, to monitor MN disease progression, we identified small regulatory microRNAs (miRNAs) that were highly enriched or exclusive in MNs. The signal for one of these MN-enriched miRNAs is detectable in spinal tap biofluid from an ALS rat model, where its levels change as disease progresses, suggesting that it may be a clinically useful marker of disease status. Furthermore, rats treated with ALS therapy have restored expression of this MN RNA marker, making it an MN-specific and drug-responsive marker for ALS rodents.

\section{Introduction}

Amyotrophic lateral sclerosis (ALS) is a fatal, adult-onset neurodegenerative disease in which motor neurons (MNs) are selec-

Received Nov. 21, 2016; revised March 16, 2017; accepted April 6, 2017.

Author contributions: M.L.H., E.D.K., J.D.D., and T.M.M. designed research; M.L.H., E.D.K., A.J.W., T.S.H., C.Y., D.R.O., R.L.M., T.C., K.M.S., T.S., T.K., J.P.R., D.H.G., N.J.M., and H.B.K. performed research; J.D.D. contributed unpublished reagents/analytic tools; M.L.H., J.D.D., and T.M.M. analyzed data; M.L.H., J.D.D., and T.M.M. wrote the paper.

This work was supported by Project5 for ALS (T.M.M.); the National Institute of Neurological Disorders and Stroke-National Institutes of Health (Grants K08NS074194 and R01NS078398 to T.M.M., Grant F31NS077781 to E.D.K., and Grant F31NS092340 to M.L.H.); the Robert Packard Center for ALS Research (T.M.M.); the University of Missouri Spinal Cord Injury and Disease Research Program (T.M.M.); and the Hope Center for Neurological Disorders. J.D.D. is supported in part by a NARSAD Independent Investigator grant from the Brain and Behavior Research Foundation. This work was also supported by access to equipment made possible by the Hope Center for Neurological Disorders and the Departments of Neurology and Psychiatry at Washington University School of Medicine. Data from the Nikon A1Rsi confocal microscope were obtained in part through the use of Washington University Center for tively lost. This progressive loss of $\mathrm{MNs}$ results in muscle denervation and atrophy, leading to death within 3-5 years of symptom onset (Pasinelli and Brown, 2006; Rothstein, 2009).

Cellular Imaging supported by Washington University School of Medicine, the Children's Discovery Institute of Washington University and St. Louis Children's Hospital, the Foundation for Barnes-Jewish Hospital, and the National Institute for Neurological Disorders and Stroke-National Institutes of Health (Grant NS086741). We thank Gregory F. Wu and Conrad C. Weihl for helpful comments and critique on this work; Pak Chan (Stanford University) for providing the hSOD1 WT rats; Klaus-Armin Nave (Max Planck Institute) for the Cnp1 Cre mouse; the Division of Neuropathology, Department of Pathology and Immunology, for assistance with autopsy tissue acquisition; Amber Salter for help with statistical analyses; and Elena Fisher for assistance with manuscript preparation.

Washington University has filed patents regarding miRNA as biomarkers and therapeutic targets for ALS. The authors declare no other competing financial interests.

Correspondence should be addressed to Timothy Miller, Department of Neurology, Washington University School of Medicine, Campus Box 8111, 660 S. Euclid Ave., St. Louis, M0 63110. E-mail: miller.t@wustl.edu.

DOI:10.1523/JNEUROSCI.3582-16.2017

Copyright $\odot 2017$ the authors $\quad 0270-6474 / 17 / 375574-13 \$ 15.00 / 0$ 
The majority of ALS cases are sporadic, whereas the remaining $10 \%$ are familial. Mutations in superoxide dismutase 1 (SOD1) were the first identified genetic cause of ALS and are responsible for $20 \%$ of familial ALS. Currently, mice and rats containing mutated human SOD1 (hSOD1) are the most widely used models and recapitulate the disease pathology faithfully.

MicroRNAs (miRNAs) are small, regulatory RNAs that regulate the translation of protein-coding RNAs. miRNAs direct translational repression by partial binding to the $3^{\prime}$ UTR of mRNAs after first being incorporated into an RNA-induced silencing complex containing Argonaute-2 (Ago2) (Gregory et al., 2005; Chekulaeva and Filipowicz, 2009; Ha and Kim, 2014). Because only partial complementarity is required for miRNA-mRNA interactions, a single miRNA can potentially regulate hundreds of mRNAs (Selbach et al., 2008). Emerging data demonstrate that miRNAs are powerful regulators of physiological and pathological cellular processes (Ardekani and Naeini, 2010; O'Connell et al., 2010; Sayed and Abdellatif, 2011). Therefore, miRNA expression is often dysregulated in disease and miRNAs have been used as both therapeutic and diagnostic targets (Chen et al., 2008; Koval et al., 2013).

Work from our lab and others found that miR-155, a glialenriched miRNA, is upregulated in the spinal cords of end-stage ALS model (SOD1 ${ }^{\mathrm{G} 93 \mathrm{~A}}$ ) mice and human autopsy (Koval et al., 2013; Butovsky et al., 2015). Inhibiting miR-155 significantly delays disease progression in SOD $1{ }^{\mathrm{G} 93 \mathrm{~A}}$ mice (Koval et al., 2013; Butovsky et al., 2015). Despite enthusiasm for this glial miRNA therapeutic approach, we hypothesized that MN miRNA changes in ALS may be equally or more important because MN loss and pathology define the onset of disease and ultimately death (Boillée et al., 2006; Ilieva et al., 2009). However, because MNs represent only $4 \%$ of the mouse spinal cord volume (Zetterström et al., 2011), probing miRNA changes in $\mathrm{MNs}$ is challenging and must be done using a comparative strategy so that the expression profiles of MNs can be discriminated from other CNS cell types. Finally, because ALS is an adult-onset neurodegenerative disease, we sought to profile miRNA expression in adult mice.

To assess miRNA expression in CNS cell types, we used a biochemical purification system, miRNA tagging and affinity purification (miRAP) (He et al., 2012), in which tagged Ago2 is expressed in particular cell types under the control of the Cre-Lox system. Because catalytically functional miRNAs must be loaded into the miRNA-processing protein Ago2 (Hammond et al., 2001; Hammond, 2005), affinity purification via antibodies against Ago2 serves to isolate active miRNAs from tissue lysates (Chi et al., 2009). Furthermore, by expressing a GFP-myc-tagged version of Ago2 only in particular cell types, miRNAs from distinct cell populations may be isolated via myc or GFP immunoprecipitation (IP) (He et al., 2012). To determine enriched miRNA expression in CNS cell types, we crossed miRAP reporter mice [lox-stop-lox-GFP-myc-Ago2 (LSLtAgo2)] to mice expressing Cre recombinase under promoters targeting all neurons, MNs, astrocytes, and myeloid cells including microglia. We discriminated MN-enriched miRNAs from other CNS cell types via a comparative analysis. The $\mathrm{MN}$-enrichment of one of these miRNAs (miR-218) has been established previously in developing MNs and was found to be important for MN function (Amin et al., 2015; Thiebes et al., 2015). Here, we confirmed the MN enrichment of miR-218 in adult MNs and demonstrated that it and other MN miRNAs may play a functional role in defining postnatal $\mathrm{MN}$ identity distinct from other spinal neurons. We predict these $\mathrm{MN}$-enriched miRNA expression profiles will broadly inform on MN biology and studies of diseases specific to MNs. As a first test of how MN-enriched miRNAs inform on MN disease, we examined how MN-enriched miRNAs change and respond to therapy in an ALS model.

\section{Materials and Methods}

Animals

All animal protocols were approved by the Institutional Animal Care and Use Committee of Washington University at St. Louis and adhered to National Institutes of Health (NIH) guidelines. All mice were bred on a congenic C57BL/6J background. To generate cell-specific GFP-mycAgo2-expressing mice, a homozygous (ROSA)26Sor ${ }^{\text {tm1(CAG-GFP/EiF2c2)Zjh }}$ (LSL-tAgo2) mouse (RRID:IMSR_JAX:017626) was bred to one of four Cre lines: Synapsin 1 (Syn)-Cre (RRID:IMSR_JAX:003966), choline acetyltransferase (ChAT)-Cre (RRID:IMSR_JAX:006410), glial fibrillary acidic protein (GFAP)-Cre (Bajenaru et al., 2002) (a gift from David H. Gutmann), or lysozyme 2 (Lyz2, LysM)-Cre (RRID:IMSR_JAX:004781). To visualize the cell types marked by GFAP and Lyz2, we used LSLtdTomato mice (RRID:IMSR_JAX:007905). Mice used in experiments were heterozygous for LSL-tAgo2 and for a cell-specific Cre driver, whereas control mice were only positive for LSL-tAgo2. C57BL/6J SOD $1{ }^{\text {G93A }}$ mice were originally purchased from The Jackson Laboratory (ID: 004435). For CSF studies, Sprague Dawley nontransgenic, hSOD1 WT (provided by Pak Chan, Stanford University) and the SOD1 ${ }^{\text {G93A }}$ (Taconic model 2148) rat lines were used.

At 9 weeks of age, mice were anesthetized with an overdose of inhaled isoflurane before being perfused with $20-30 \mathrm{ml}$ of cold $1 \times$ PBS. Perfusion was critical for the elimination of Lyz2-labeled monocytes in the blood. Whole spinal cords and whole brainstems (pons and medulla) were isolated, flash frozen in liquid nitrogen, and stored at $-80^{\circ} \mathrm{C}$.

\section{Histology}

Double-label cell type expression. Free-floating $50 \mu \mathrm{m}$ sections from $4 \%$ paraformaldehyde (PFA) fixed brain and spinal cord tissue from either male or female mice were used for immunohistochemistry. Goat-antiChAT (1:200, Millipore AB144; RRID:AB_11212843) and chicken-antiGFP (1:250, Aves, GFP-1020; RRID:AB_10000240) were applied to the tissues overnight at $4^{\circ} \mathrm{C}$.

In situ hybridization. $20 \mu \mathrm{m}$ sections from ChAT-RpL10a-GFP (a gift from Joseph D. Dougherty) mice were fixed in 4\% PFA and acetylated. No proteinase $\mathrm{k}$ digestion was performed. $5^{\prime}, 3^{\prime}$-DIG-labeled anti-miR218 probes (Exiqon) were hybridized at $49^{\circ} \mathrm{C}$ overnight. Cy5 Tyramide Signal Amplification (1:50, PerkinElmer, NEL705A001KT) was performed. Chicken anti-GFP antibody (1:1000, Aves Laboratory, GFP1020; RRID:AB_10000240) was used to recognize ChAT-L10a-GFP ${ }^{+}$ MNs. Secondary antibodies were applied to the tissue for $1 \mathrm{~h}$. All sections were stained with DAPI. Slides were mounted and coverslipped with Fluoromount (Southern Biotech, 0100-01). Images were acquired with a Nikon A1Rsi confocal microscope. For formatting, ImageJ (RRID: SCR_003070) and Adobe Photoshop CS6 Extended were used.

miR-218 fluorescence signal quantification. In situ hybridization slides were observed using a Nikon A1Rsi confocal microscope. All images were taken at a $20 \times$ magnification with the same laser power and pinhole size and the detector was set so that no saturation occurred. To determine miR-218 fluorescence signal, three background measurements with no ChAT-L10a-GFP staining were measured. Each MN was outlined according to ChAT-L10a-GFP staining and the fluorescence signal of miR218 was measured using ImageJ as described previously (McCloy et al., 2014). Image analyses were conducted by a blinded reviewer.

SMI-32 motor neuron counts. Free-floating $40 \mu \mathrm{m}$ sections from $4 \%$ PFA fixed lumbar spinal cord tissue from either male or female rats were used for immunohistochemistry. Mouse-anti-SMI-32 (1:500, BioLegend, SMI-32; RRID:AB_2315331) was applied to the tissues overnight at $4^{\circ} \mathrm{C}$. Images were acquired with a Nikon A1Rsi confocal microscope at $20 \times$ magnification. MN counts were limited to the anterior horn of the lumbar spinal cord. The number of MNs for each rat is an average of at least six sections per rat where both sides of the anterior horns were analyzed. The counting was performed by a blinded reviewer.

\section{MiRAP}

Brainstem and spinal cords from saline perfused, 63-d-old mice (3 males and 3 females/line) were harvested, flash frozen in liquid nitrogen, and 
stored at $-80^{\circ} \mathrm{C}$. Tissue was homogenized and miRAP was conducted as described previously (He et al., 2012). A BCA assay was performed on all tissue homogenates to normalize input to the lowest protein concentration. Next, $700 \mu$ l of QIAzol (Qiagen) was added directly to the beads and stored at $-20^{\circ} \mathrm{C}$. miRAP was performed identically in LSL-tAgo2, ChAT-Cre, SOD1 ${ }^{\text {G93A }}$ mice using spinal cord tissue harvested at $70 \mathrm{~d}$ (presymptomatic) and $140 \mathrm{~d}$ (symptomatic).

miRNA extraction and quantification

RNA was isolated using miRNeasy kits per manufacturer's instructions (Qiagen). miRNA microarrays were performed with preamplification using low-density rodent MiRNA A + B cards set 3.0 (Life Technologies) on a $7900 \mathrm{HT}$ qPCR machine for 40 cycles. Arrays were performed on tissue from 3 male mice/line. Microarray miRNA targets were confirmed with individual TaqMan miRNA qPCR assays (Life Technologies) in technical duplicates on an Applied Biosystems 7500 Fast Real-Time PCR System. Cell-type-enriched miRNAs were confirmed with individual assays using tissue from three male and three female mice per line.

\section{CSF collection and miRNA extraction and quantification}

CSF was obtained from both male and female rats anesthetized with 5\% isoflurane via puncture of cisterna magna and centrifuged at $1000 \times g$ for 10 min at $+4^{\circ} \mathrm{C}$ before freezing supernatant at $-80^{\circ} \mathrm{C}$. The same volume of CSF is used to extract miRNA with the miRcury RNA Isolation Kit Biofluids (Exiqon). MS2 carrier RNA ( $1 \mu \mathrm{g}$ of RNA/100 $\mu$ l of CSF) was added to CSF to maximize miRNA recovery (Andreasen et al., 2010). RT-qPCR was performed using the miRCURY LNA Universal RT and ExiLENT SYBR green kit (Exiqon). Data were analyzed using the $2^{- \text {ddCT }}$ method and miR-103a-3p, miR-191, and miR-24 were used as a normalization control (per the manufacturer's recommendation).

\section{SOD1 antisense oligonucleotide (ASO) treatment}

SOD $1{ }^{\mathrm{G} 93 \mathrm{~A}}$ rats at $65 \mathrm{~d}$ of age were anesthetized with $5 \%$ isoflurane and given a $30 \mu \mathrm{l}$ intrathecal bolus injection of $1000 \mu \mathrm{g}$ of ASO (hSOD1: TTAATGTTTATCAGGAT; scrambled: CCTATAGGACTATCCAGGAA) or artificial CSF (aCSF) (Tocris Bioscience) between L4 and L5 of the lumbar spinal cord. Cohorts were gender and litter matched; both male and female rats were used. CSF and spinal cord were harvested at $115 \mathrm{~d}$ of age. All surgeries and downstream analyses were done by personnel blinded to treatment groups.

\section{Hindlimb grip strength}

Grip strength was assessed weekly using a grip strength meter (DFIS-2 series digital force gauge; Columbus Instruments). The grip strength of each rat was measured five times consecutively and the average of the five readings was recorded as the grip strength. Assessors were blinded to treatment groups.

\section{Primary Hb9-GFP MN cultures}

Primary Hb9-GFP MN cultures were obtained as described previously (Wang and Marquardt, 2012). Briefly, the ventral spinal cord was dissected from male and female Hb9-GFP E12.5 embryos. The ventral column was digested using papain (Worthington) and MNs were dissociated and strained through a $40 \mu \mathrm{m}$ strainer. MNs were isolated using a density gradient of 3\% and 9\% optiprep (Sigma-Aldrich) and centrifugation. A total of 100,000 cells were plated on poly-ornithine- (SigmaAldrich) and laminin (Sigma-Aldrich)-coated 24-well plates.

\section{miR-218 release and lactate dehydrogenase $(L D H)$ assay}

A total of 100,000 Hb9-GFP MNs were plated and subsequently treated with $1 \mathrm{~mm}$ sodium arsenite (Fluka) for $4 \mathrm{~h}$. Next, $200 \mu \mathrm{l}$ of medium was harvested at 0,2 , and $4 \mathrm{~h}$ and centrifuged at $1000 \mathrm{rpm}$ for $5 \mathrm{~min}$ to pellet cells. Then, $175 \mu \mathrm{l}$ of medium was removed, leaving the pellet undisturbed, and $125 \mu \mathrm{l}$ of medium was mixed with 5 volumes of QIAzol and RNA was extracted using the miRNeasy kit (Qiagen). Finally, $50 \mu \mathrm{l}$ of medium was used for LDH assay (Roche). For induced pluripotent stem cell (iPSC)-derived MN cultures, cells were treated with puromycin $(1 \mu \mathrm{g} / \mathrm{ml})$ for $72 \mathrm{~h}$.

\section{Fibroblast collection and reprogramming}

Fibroblasts were grown in Glutamax (Invitrogen) supplemented with $10 \%$ serum. iPSC lines were created and initially characterized with an
NIH-sponsored commercial agreement with iPierian as described previously (Donnelly et al., 2013).

\section{Human iPSC-derived MN-enriched cultures}

iPSCs were maintained in E8 (Thermo Fisher Scientific) and passaged once every 5-6 d using dispase (Stemcell Technologies). Partially differentiated colonies were removed manually before each passage and before starting the differentiation process. iPSCs were differentiated to neuroprogenitor cells and then to MNs as described previously (Boulting et al., 2011). To enrich the population of neurons, compound E (Santa Cruz Biotechnology) and AraC (20 $\mu \mathrm{m}$; Sigma-Aldrich) was added to iPSC cultures after day 30 to reduce the number of dividing cells (mostly glial cell populations). After $45 \mathrm{~d}$ of differentiation, the cells began to exhibit more mature neuron and $\mathrm{MN}$ phenotypes. Cells were then replated at $\sim$ day 45 and $\operatorname{AraC}(20 \mu \mathrm{M})$ was added the following day. This resulted in a relatively pure population of neurons expressing MN markers.

\section{Human tissues and cells}

Autopsy tissues were obtained from patients who consented to participate in Washington University's autopsy program (ALS patients) or consented to tissue donation through the National Disease Research Interchange program (non-ALS). Cervical spinal cord autopsy tissue obtained from ten ALS patients and four non-ALS control patients was used for miRNA analysis. iPSCs were reprogrammed from fibroblasts derived from skin biopsies of subjects with or without ALS under Johns Hopkins institutional review board protocols (NA_00021979: Skin Biopsies to Generate Cell Lines for Study of Amyotrophic Lateral Sclerosis, approved 10/16/2008, and NA_00033726: Generation and Characterization of Cell Lines for Amyotrophic Lateral Sclerosis, approved 1/19/2010). Consents included the authorization to use DNA, fibroblasts, or cell lines derived from fibroblasts for research purposes only.

\section{Statistical and data analysis}

Data are presented as mean \pm SEM. All statistical tests were conducted using R's Bioconductor toolkit, Microsoft Excel, or GraphPad Prism 6 software. Array data were normalized by global LoessM in R studio as described previously (Risso et al., 2009). Adjusted p-values were calculated using the Benjamini-Hochberg correction (Klipper-Aurbach et al., 1995).

Differentially expressed from nontransgenic. To account for background miRNA expression associated with the myc-IP, we performed TaqMan miRNA microarrays on RNA from myc IP of both brainstem and spinal cord of littermate controls not expressing tAgo2. We determined background cycle threshold (CT) cutoffs empirically for each individual miRNA and used these data to eliminate any miRNA not significantly enriched over background.

For a given sample, data were excluded for a miRNA if it failed to be expressed at a significant level over the corresponding microarray data from three myc-IP miRNA extractions from negative control mice matched by tissue type. The criteria for differential expression were as follows: (1) the miRNA must be expressed in at least two of three replicates (three of four for Ago2); (2) the median expression of the triplicates for a given miRNA must be CT $<35$ (CT $<37$ for Ago2); and (3) the highest CT of the triplicates for a given miRNA must be $2 \mathrm{CT}<$ the median CT of the nontransgenics. Specifically, the number of miRNAs in each cell type that were found to be expressed significantly over noise were as follows: 257 (ChAT, brainstem), 295 (ChAT, spinal cord), 406 (Syn, brainstem), 417 (Syn, spinal cord), 325 (GFAP, brainstem), 295 (GFAP, spinal cord), 123 (Lyz2, brainstem), 56 (Lyz2, spinal cord), 484 (Ago2, brainstem), and 467 (Ago2, spinal cord).

Endogenous miRNA controls. To identify putative housekeeping miRNAs, we used the following criteria. Using the LoessM-normalized CTs, we subsetted for miRNAs with a low SD $(<1)$ among the triplicates. The mean CT of the triplicates had to be $<24$ for all cell types. miR-24, miR-30c, and miR-191 were the top three miRNAs that met these criteria.

Pairwise comparisons. For miRNAs that met the criteria for being differentially expressed from the nontransgenics, relative expression data were generated for all pairwise comparisons between cell types in both tissues. Significant changes in miRNA expression profiles were determined by empirical Bayes given the low sample number, the large number of targets (672 miRNAs), and the inability to assume normal distribution (Smyth, 
2004). Adjusted $p$-values were calculated using the Benjamini-Hochberg correction (Klipper-Aurbach et al., 1995).

Heat map. miRNAs were included in the heat map illustration (see Fig. $1 D$ ) if a given miRNA was found to have significant differential expression $(\log 2 \mathrm{FC}>2$ and $p<0.01)$ in at least one comparison.

Specificity index. We used the R Package pSI (Xu et al., 2014) to define which miRNAs were enriched in each cell type compared with all others, with minor adaptations to the input for use with qPCR microarrays.

$M N$-enriched miRNAs. The top six miRNAs enriched in MNs were defined by the following criteria: (1) the geomean of the ChAT triplicates from the arrays $\leq 30 \mathrm{CT}$ and differentially expressed from nontransgenic for both tissues; (2) fold change $\geq 1.75$ in all spinal cord comparisons; and (3) adjusted $p$-value $\leq 0.1$ in ChAT versus Syn comparison in either brainstem or spinal cord.

Comparison with MN-depleted $m R N A$. miRNA target predictions were downloaded from mirDB (Wong and Wang, 2015) and targets with a confidence $>60$ were extracted for each of the five MN-enriched miRNAs. These targets were tested for overlap with mRNAs differentially translated between postnatal MN and postnatal spinal cord neurons (R. Ouwenga, A. Lake, A. Yoo, J. Dougherty, Washington University, personal communication). These data are available on Gene Expession Omnibus (accession number pending). Differentially translated genes were defined as $\log \mathrm{FC}>1$ and $p<0.05$ by negative binomial test implemented in EdgeR. One-tailed Fisher's exact test with Benjamini-Hochberg multiple testing correction was used to test for overlap. Pathway analysis was performed using DAVID 6.8 (da Huang et al., 2009a, 2009b).

\section{Results \\ Generation of cell-specific expression of GFP-myc-Ago2 in CNS tissues}

We adapted the miRAP method developed by He et al. (2012) to express tAgo2 in specific cell populations relevant to ALS. Doubletransgenic mice carrying alleles of Cre recombinase under various promoters and LSL-tAgo2 in the Rosa26 locus were generated (Fig. $1 A)$. To target cell-type-specific expression of Cre recombinase, and thus cell-type-specific expression of tAgo2, we used existing Cre lines with the following promoters: Syn (Hilfiker et al., 1999), ChAT (Rotolo et al., 2008), GFAP (Bajenaru et al., 2002), or Lyz2 (Clausen et al., 1999; Faust et al., 2000) targeting a panneuronal-, MN-, astrocyte-, or microglia-containing cell population, respectively.

We harvested brainstems and spinal cords from replicate adult mice carrying both Cre recombinase and LSL-tAgo2 alleles (experimental mice) or only LSL-tAgo2 (negative controls). Double-label immunofluorescence histology using a cell-specific antibody and an antibody against GFP indicated that tAgo2 was expressed in the desired cell types (data not shown). In ChAT-Cre double-transgenic mice, tAgo2 expression was restricted to the $\mathrm{ChAT}^{+}$brainstem motor nuclei and spinal MNs (Fig. 1B). After BCA normalization for protein input, miRAP was performed on these tissues using either myc or Ago2 antibodies (Fig. 1C). The resulting miRNAs were isolated and assayed via TaqMan miRNA microarrays v3.0 (A+B cards). On a global level, the miRNA expression profiles for CNS cell types are distinct. After unsupervised 3D principal component analysis (PCA), we found that miRNA expression profiles were sufficient to cluster samples by their cell type of origin (Fig. 1E). Furthermore, miRNA expression profiles from IP of tagged and untagged Ago2 from each transgenic mouse clustered together in PCA, indicating that the global miRNA expression in these mice is comparable (Fig. 1E). Hierarchical heat maps also demonstrated that these CNS cell types can be identified by their unique miRNA expression profiles (Fig. 1D).

Because U6 snRNA, often used for miRNA normalization, is not typically loaded into Ago2, miRAP studies must use endogenous miRNA controls for normalization of RT-qPCR data. Using this global miRNA array data, we identified miRNAs that are consistently expressed across CNS cell types in both brainstem and spinal cord: miR-24, miR-30c, and miR-191 (Fig. $1 F$ ). The use of these miRNAs as endogenous controls for normalizing RT-qPCR data will greatly aid in future studies of miRNAs in the CNS. Furthermore, these results align well with previous reports identifying putative housekeeping miRNAs (Peltier and Latham, 2008).

\section{Identification of MN-enriched and other CNS cell-type-enriched miRNAs}

To identify MN-enriched miRNA expression, we used a heuristic approach followed by the specificity index (pSI), an algorithm designed to define the set of transcripts enriched in each cell population compared with all others at a given permutation based statistical threshold. We previously validated the performance of this algorithm and its robustness to minor contamination in a given population (Dougherty et al., 2010). Using the heuristic approach, we identified six miRNAs that were enriched in either brainstem or spinal MNs compared with all other neurons ( $\geq 1.75$-fold, adjusted $p \leq 0.1)$ and abundantly expressed (CT $\leq 30)$ with the arrays. All six of these transcripts were also enriched in either brainstem or spinal cord MNs compared with all other samples of $p \leq 0.1$ using the permuted pSI statistic. Using individual RTqPCR assays at a higher power $(n=6)$, we confirmed the MNenrichment of five of the top six miRNAs (Fig. 2A) (miR-380-5p could not be confirmed due to nonspecificity of TaqMan primers: repeated amplification in no-template control). miR-218-5p and its lesser abundant $3 p$ strand exhibited the strongest enrichment in adult MNs compared with all other spinal neurons (Fig. 2A), which had been demonstrated previously in embryonic MNs (Amin et al., 2015; Thiebes et al., 2015). The MN enrichment of miR-218 in adult mouse spinal cord was further confirmed by in situ hybridization. miR-218 is detected predominantly in the $\mathrm{ChAT}^{+} \mathrm{MNs}$ in the anterior horns of the spinal cord by in situ, but not in other cell types (Fig. 2B). Because oligodendrocytes are also abundant in the CNS, we performed miRAP independently on LSL-tAgo2, Cnp1-Cre mice (Lappe-Siefke et al., 2003) and performed individual RT-qPCR assays to verify that MNenriched miRNAs were not abundant in oligodendrocytes in the spinal cord. All five $\mathrm{MN}$-enriched miRNAs were significantly enriched in $\mathrm{ChAT}^{+} \mathrm{MNs}$ compared with $\mathrm{Cnp}^{+}$oligodendrocytes in the spinal cord (Fig. 2C). As expected, miR-338-3p, a miRNA known to be enriched in oligodendrocytes, was $\sim 25$-fold more abundant in oligodendrocytes than MNs (Zhao et al., 2010; de Faria et al., 2012) (Fig. 2D).

Because ALS is a disease characterized by MN loss, the focus of this work was to use an in vivo approach that would be amenable to defining MN-enriched miRNAs compared with other CNS cell types. However, because dysregulation in glia also plays an important role in ALS and other disorders (Boillée et al., 2006; Yamanaka et al., 2008; Ilieva et al., 2009), we have also analyzed our data to define sets of miRNAs that were enriched in astrocytes, microglia, and all other neurons. All comparisons made using LoessM-normalized array data are included in Fig. 1-1 available at https://doi.org/10.1523/JNEUROSCI.3582-16.2017.f1-1.

\section{mRNA targets of MN-enriched miRNAs}

To determine whether $\mathrm{MN}$-enriched miRNAs might functionally regulate $\mathrm{MN}$ translational profiles, we examined the ribosomal occupancy of the predicted targets of the MN-enriched miRNAs using translating ribosome affinity purification (TRAP). Comparing the ribosome-bound transcript levels between MNs (ChAT-TRAP mouse line) with ribosome-bound transcripts from all spinal 
A

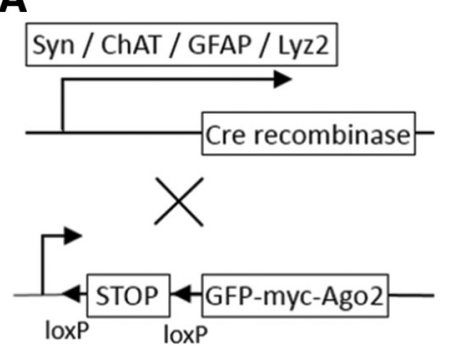

D

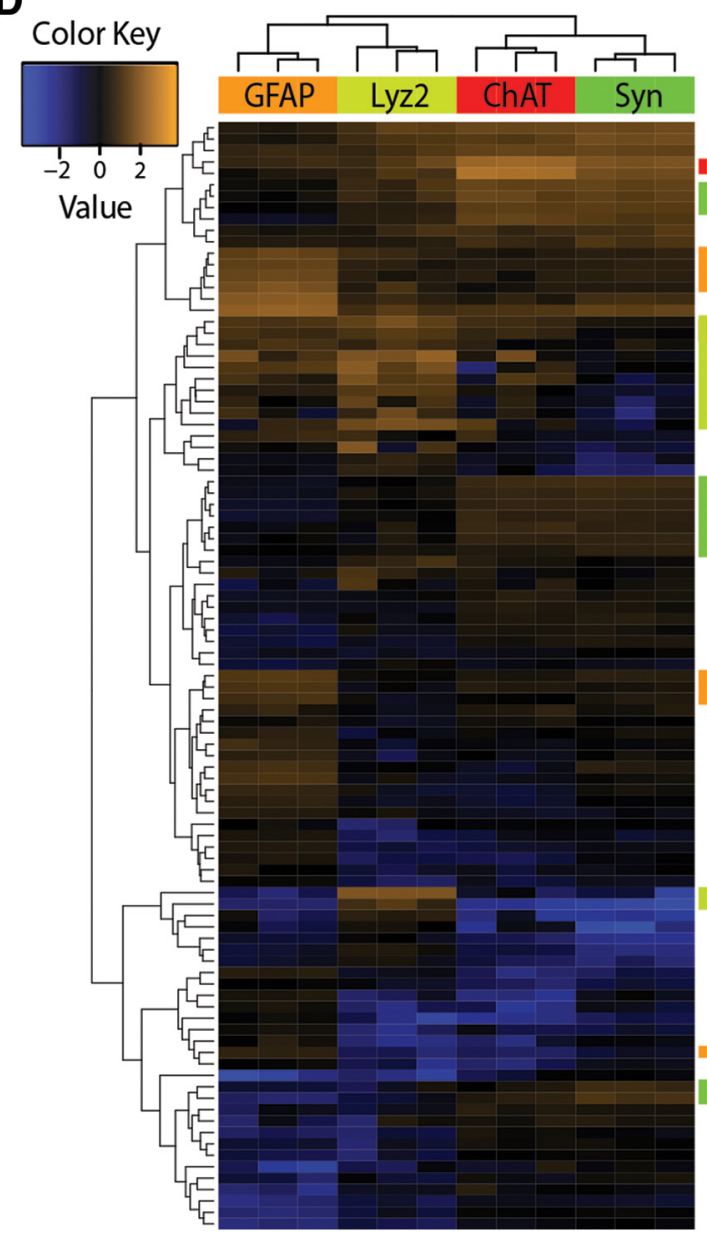

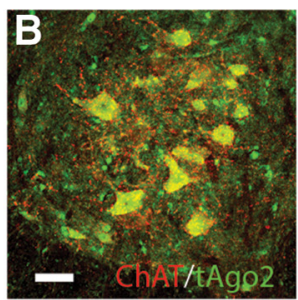
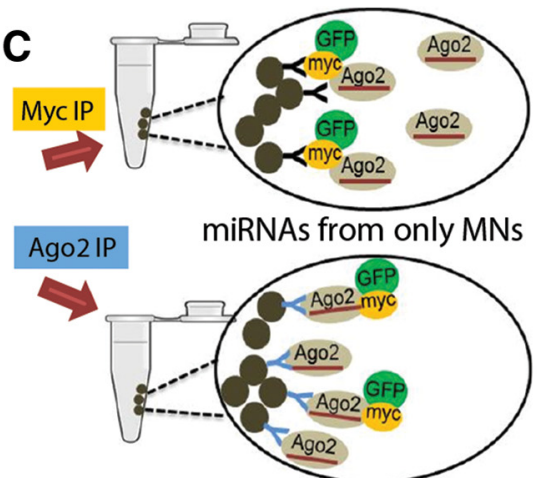

miRNAs from all cell types

$\mathbf{E}$

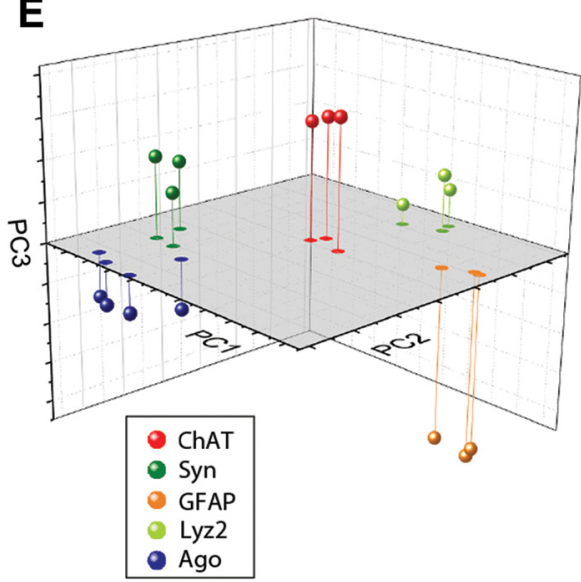

F ChAT GFAP Lyz2 $\frac{\text { Syn }}{\text { Shainstem }} \frac{\text { ChAT GFAP Lyz2 }}{\text { Spynal Cord }}$

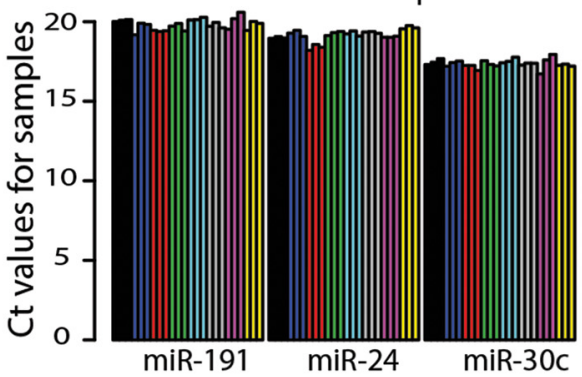

Figure 1. Generation of cell-specific expression of GFP-myc-Ago2 and identification of CNS cell-type-enriched miRNA expression profiles. $A$, Mice were generated to express Cre recombinase under cell-type-specific promoters. Cre recombinase drives expression of a tagged miRNA-binding protein, Ago2, in the desired cell type. $\boldsymbol{B}$, Spinal cord sections from transgenic mice were stained for ChAT (red; MNs) and GFP (green). Scale bar, $50 \mu \mathrm{m}$. C, Schematic of miRAP demonstrating selective expression of GFP-myc-tagged Ago2 in MNs, which allows for IP of myc to isolate miRNAs from only MNs or IP of Ago2 to isolate miRNA from all spinal cord cell types. D, Hierarchical heat map clustering demonstrating that spinal cord CNS cell types can be identified by their unique miRNA expression profiles. Colored bars along the right side of the heat map correspond to miRNAs enriched in distinct CNS cell types (orange $=$ GFAP/astrocytes, yellow $=$ Lyzz/microglia, red $=$ ChAT/MNs, green = Syn/all neurons). Values are expressed as log2 fold change. E, 3D PCA illustrating that CNS cell types cluster according to their miRNA expression profiles. The replicates of each spinal cord cell type cluster with each other more so than with any other cell type. miRNA expression from Ago2 IP from one of each of these four mice cluster, indicating that global miRNA signatures are comparable. $\boldsymbol{F}$, Putative endogenous miRNA controls for CNS cell types. Using global LoessM normalization of the miRNA microarray data, miR-191, miR-24, and miR-30c were found to be expressed consistently across CNS cell types in both brainstem and spinal cord. For the CNS cell types analyzed here, these miRNAs could serve as controls for normalizing miRNA RT-qPCR data. The LoessM-normalized miRNA array data for CNS cell types in both brainstem and spinal cord and the miRNAs found to be enriched in these cell types can be found in Fig. 1-1 available at https://doi.org/10.1523/JNEUROSCI.3582-16.2017.f1-1.

neurons (Snap25-TRAP mouse line), we found a significant preponderance of targets of both mir-218-5p and mir-133a-3p among those mRNAs relatively decreased in the MNs and increased in all other neurons (Fig. 3A). For mir-218-5p, this is consistent with prior work suggesting that mir-218 suppresses mRNAs characteristic of interneurons in developing embryonic MNs (Amin et al., 2015). Importantly, our work suggests miR-
218 retains its MN specificity in adults and may be essential in maintaining $\mathrm{MN}$ identity distinct from other spinal neurons in addition to interneurons. We were also able to identify a similar role for mir-133a-3p, the predicted targets of which include Foxp2 and Lhx5, which are both transcription factors known to regulate the fate of non-MNs in the spinal cord (Dasen et al., 2008; Pillai, 2007). Intriguingly, miR-133a has been studied ex- 
A

\begin{tabular}{lcc}
\multicolumn{1}{c}{ miRNA } & Fold-Change & P-value \\
\hline miR-218 & 11.9 & 0.0001 \\
miR-218-2-3p & 11.9 & $<0.0001$ \\
miR-138 & 3.2 & $<0.0001$ \\
miR-133a & 2.8 & $<0.0001$ \\
miR-1193 & 3.7 & 0.0007
\end{tabular}

B
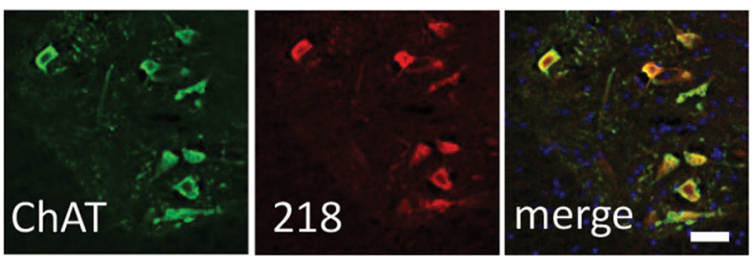

C

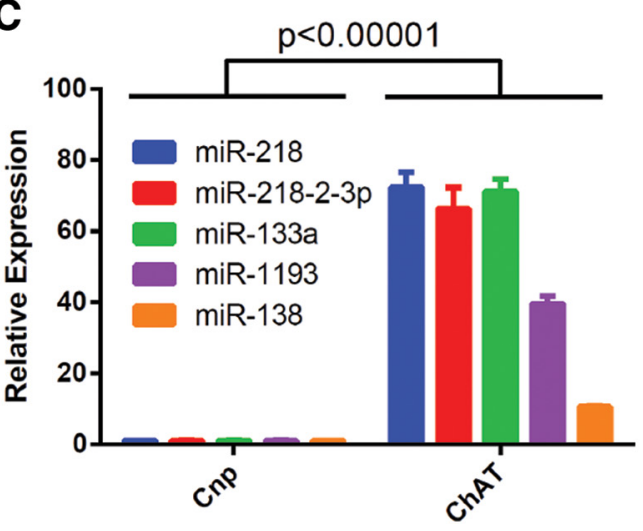

D

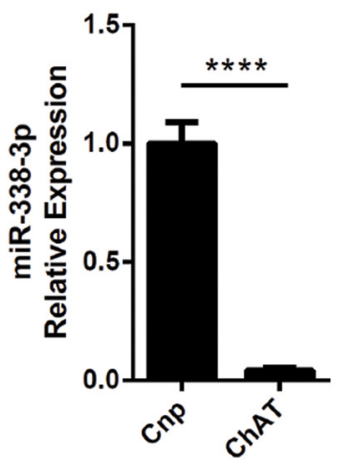

Figure 2. Identification of MN-enriched miRNAs in CNS tissues. $\boldsymbol{A}$, Individual RT-qPCR assays confirming the specificity of MN-enriched miRNAs compared with all other spinal cord neurons. $n=6$. Values are expressed as means. $\boldsymbol{B}$, miR-218 (red) is detected in $\mathrm{ChAT}^{+}$(green) MNs in the anterior horns of adult mouse spinal cord by in situ hybridization. Scale bar, $50 \mu \mathrm{m} . \mathrm{C}$, miRAP of LSL-tAg02, Cnp1-Cre mice followed by individual RT-qPCR assays indicates that MN-enriched miRNAs are significantly more abundant in MNs than oligodendrocytes in the spinal cord. $n=5-6$. D. The oligodendrocyte-enriched miRNA miR-338-3p is more abundant in oligodendrocytes than MNs in the spinal cord, indicating that miRAP works in LSL-tAg02, Cnp1-Cre mice. $n=$ 5-6. Values are expressed as mean \pm SEM. Relative expression normalized to a geometric mean of miR-30c, miR-24, and miR-191 $(\boldsymbol{A}, \boldsymbol{C}, \boldsymbol{D})$. Student's unpaired, two-tailed $t$ test with Bonferroni correction for multiple (five, $\boldsymbol{A})$ or (six, $\boldsymbol{C}$ and $\boldsymbol{D}$ combined) comparisons. ${ }^{* * *} p \leq 0.0001$.

tensively in the context of muscle (Chen et al., 2006), but this work suggests that it may also function in the spinal cord to reinforce $\mathrm{MN}$ identity. Because miRNAs repress mRNA translation, it is expected that targets of MN miRNAs would be more highly expressed in non-MNs (Snap25). Using DAVID analysis, we found that genes associated with transcription and transcription regulation were represented significantly in the non-MN (Snap25)-enriched genes that are regulated by MN miRNAs (Fig. $3 B$ ). The miR-218 (green) and miR-133a (blue) targets associated with transcription are labeled. These analyses suggest that MNenriched miRNAs play a functional role in defining postnatal $\mathrm{MN}$ identity.

\section{Depletion of MN-enriched miRNAs in spinal cord from ALS rodent models and patients}

To determine whether MN-enriched miRNAs are relevant for MN disease, we characterized their expression in the spinal cords of ALS rodent models and human ALS patient autopsies. In our congenic ALS mouse model [B6.Cg-Tg(SOD1 $\left.{ }^{\mathrm{G} 93 \mathrm{~A}}\right) 1 \mathrm{Gur} / \mathrm{J}$ ] colony (Wooley et al., 2005), disease onset typically occurs $\sim 130 \mathrm{~d}$, as marked by time to peak weight. We performed RT-qPCR on SOD $1^{\text {G93A }}$ spinal cord harvested at 56,84,105, 126, and $147 \mathrm{~d}$, as well as at end stage (marked by animal's inability to right itself within $30 \mathrm{~s}$ ). As was anticipated for a disease that causes $\mathrm{MN}$ loss, there was a robust and highly significant temporal depletion of the MN-enriched miRNAs miR-218 and miR138 in SOD $1{ }^{\text {G93A }}$ spinal cords beginning as early as $126 \mathrm{~d}$ (Fig. 4A). This depletion was maximized in the end-stage ALS mouse model spinal cord. Following a similar trend, pan-neuronal enriched miRNAs miR-382 and miR-672 were decreased, but not significantly depleted, in ALS mouse model spinal cord, even at end stage (Fig. $4 B$ ). In ALS model rats, disease onset similarly occurs between 120 and $140 \mathrm{~d}$. Like ALS mice, MN-enriched miRNAs were also more significantly depleted than panneuronal miRNAs in SOD1 ${ }^{\text {G93A }}$ rat spinal cords (Fig. 4C). Finally, miR-218 was also significantly depleted in ALS patient autopsy spinal cord compared with nonneurodegenerative disease autopsy spinal cord controls (Fig. 4D). Both ALS rodent models and human patient autopsy spinal cord tissue indicate a robust depletion of MN-enriched miRNA expression, consistent with MN loss throughout disease progression. These data in ALS models and human ALS validate our rigorously defined list of MN-enriched miRNAs as being relevant for $\mathrm{MN}$ disease. We hypothesize that these miRNAs will inform broadly on MN biology and MN disease.

\section{miR-218 levels are maintained in surviving MNs in ALS mice}

Although miR-218 depletion in the ALS rodent model and ALS patient autopsy spinal cord tissue is likely due to MN loss, it is possible that miR-218 is downregulated in ALS MNs. It was shown recently that genetic ablation of miR-218 results in $\mathrm{MN}$ degeneration (Amin et al., 2015), so it is conceivable that decreased miR-218 contributes to $\mathrm{MN}$ degeneration in adult MNs in ALS. To test this hypothesis we used two orthogonal approaches: First, we performed miRAP on LSL-tAgo2, ChAT-Cre, SOD $1{ }^{\text {G93A }}$ mice to probe miR-218 expression in ALS MNs and, second, we examined miR-218 expression in $\mathrm{ChAT}^{+} \mathrm{MNs}$ in control and SOD1 ${ }^{\text {G93A }}$ mouse spinal cord tissue by in situ hybridization. In whole SOD $1^{\mathrm{G} 93 \mathrm{~A}}$ mouse spinal cord tissue, miR-218 was not depleted significantly until $126 \mathrm{~d}$. Therefore, we probed miR-218 expression in ALS MNs at 70 and $140 \mathrm{~d}$ and found that miR-218 levels were not significantly changed in the surviving MNs from presymptomatic to symptomatic time points (Fig. 5A). To confirm this finding, we performed miR-218 in situ hybridization using spinal cord tissue from $140 \mathrm{~d} \mathrm{SOD} 1^{\mathrm{G} 93 \mathrm{~A}}$ and littermate control mice. We found that the miR-218 fluorescence signals were also not significantly different (Fig. $5 \mathrm{~B}, \mathrm{C}$ ), but the number of $\mathrm{ChAT}^{+} \mathrm{MNs}$ per unit area were, confirming that $\mathrm{ChAT}^{+} \mathrm{MNs}$ were lost in ALS mouse model spinal cords (Fig. 5C,D). Together, these two ap- 
A

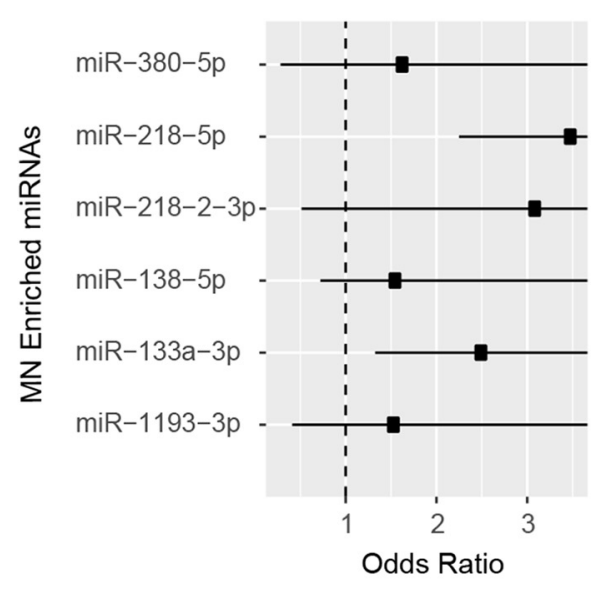

B

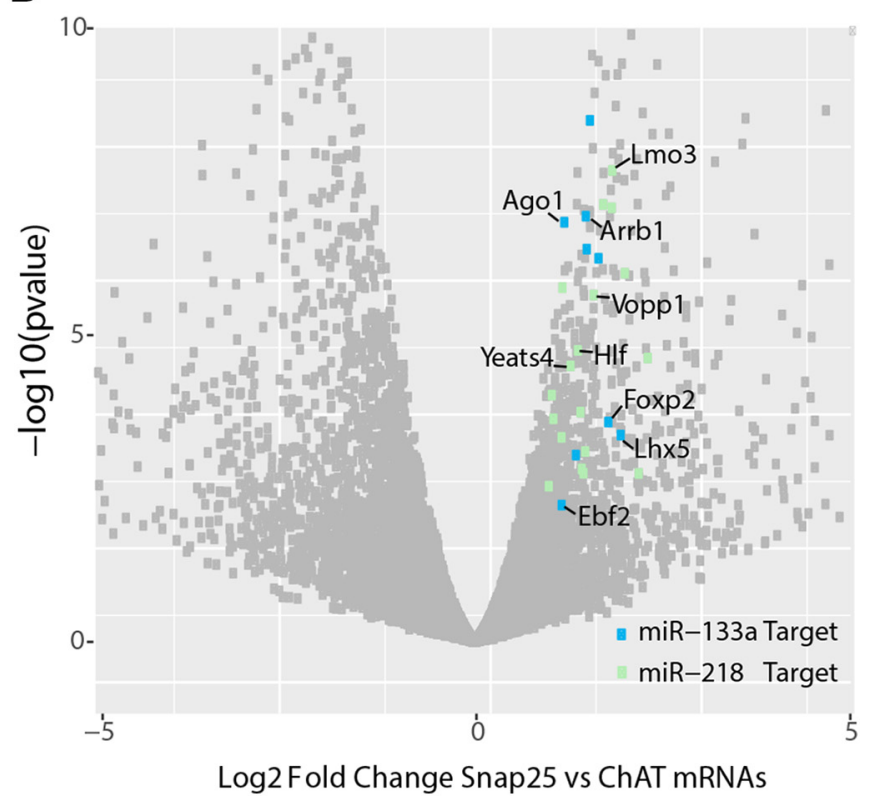

Figure 3. MN-enriched miRNAs repress non-motor neuron transcription-associated mRNA expression. $A$, Forest plot indicating the odds ratio of MN depleted mRNAs (Snap25 increased mRNAs) having target binding sites of MN-enriched miRNAs. $\boldsymbol{B}$, Volcano plot indicating the Snap25-enriched mRNAs containing miR-218 (green) or miR-133a (blue) binding sites. The labeled mRNAs are associated with transcription and transcription regulation. These terms were significantly represented ( $p=0.022$ and 0.033 , respectively, Benjamini-Hochberg corrected) in the Snap 25 upregulated mRNAs containing MN-enriched miRNA-binding sites using DAVID analysis.

A MN-Enriched miRNAs in ALS
mouse model spinal cord

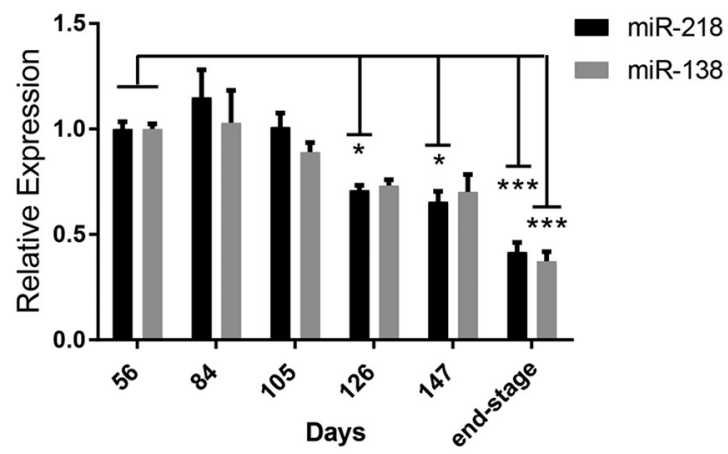

C

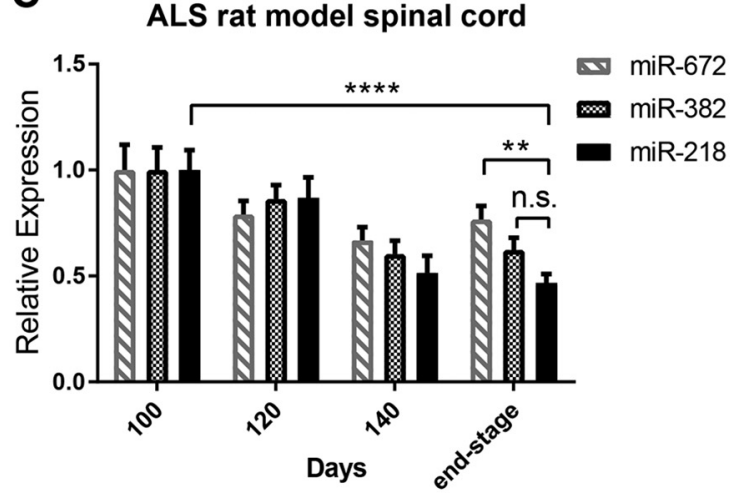

B

Pan-Neuronal Enriched miRNAs in ALS mouse model spinal cord

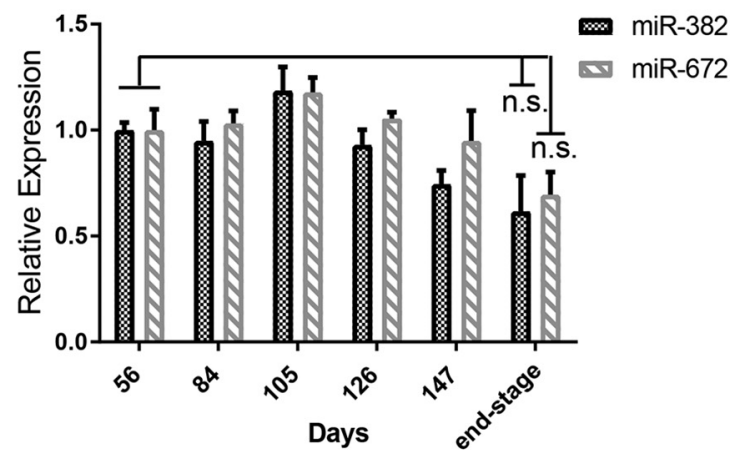

D
miR-218 in Human ALS Autopsy Spinal Cord

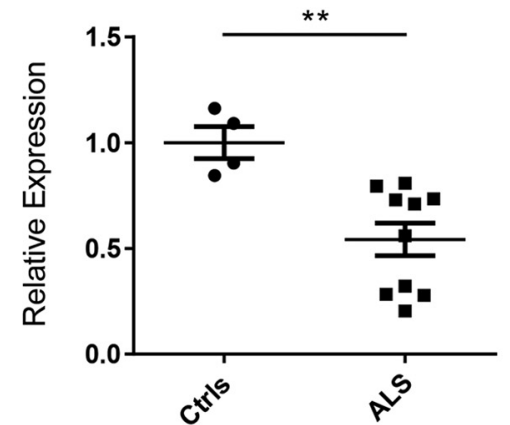

Figure 4. MN-enriched miRNAs are depleted temporally in ALS rodent model and human patient spinal cord. $A$, The MN-enriched miRNAs miR-218 and miR-138 are significantly depleted in ALS mouse $\left(S O D{ }^{693 A}\right)$ model spinal cord. This depletion occurs temporally and is maximized at end stage. $n=3-4$. B, Pan-neuronal enriched miRNAs are not significantly depleted in ALS mouse model spinal cord, even at end stage. $n=3-4$. C, MN-enriched miR-218 is significantly depleted in ALS rat model spinal cord and more so than the pan-neuronal miRNAs miR-382 and miR-672. $n=4-5$. D, miR-218 is significantly depleted in human ALS patient autopsy spinal cord compared with age-matched controls. $n=4-10$. Values are expressed as mean $\pm S E M$. ${ }^{*} p \leq 0.05$, ${ }^{* *} p \leq 0.01$, ${ }^{* * *} p \leq 0.001,{ }^{* * * *} p \leq 0.0001$, one-way ANOVA with multiple comparisons (Dunnett's) (A), Student's unpaired, two-tailed $t$ test $(\boldsymbol{B}, \boldsymbol{D})$, and two-way ANOVA ( $(\boldsymbol{C})$. Relative expression is normalized to RNA input and endogenous miRNA control miR-24 $(\boldsymbol{A}, \boldsymbol{B})$ or U6 snRNA $(\boldsymbol{C}, \boldsymbol{D})$. 
A

C

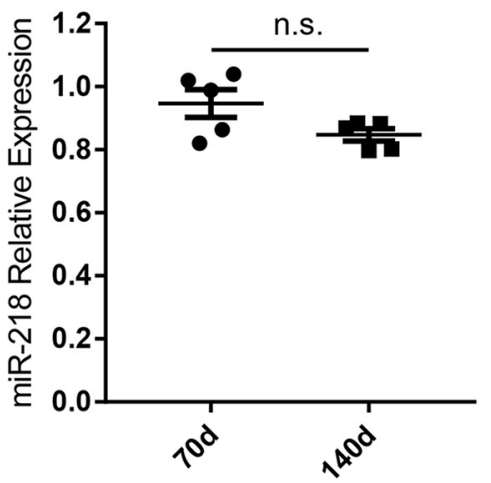

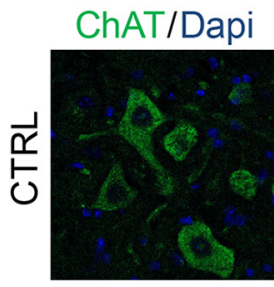

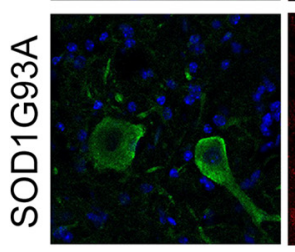

B

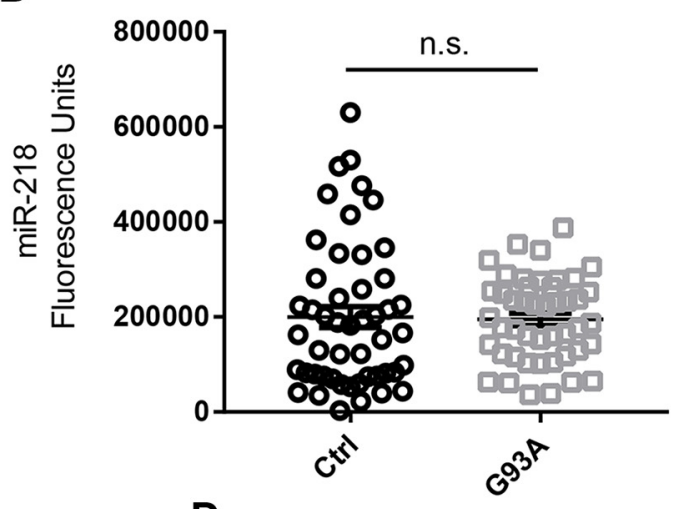

D
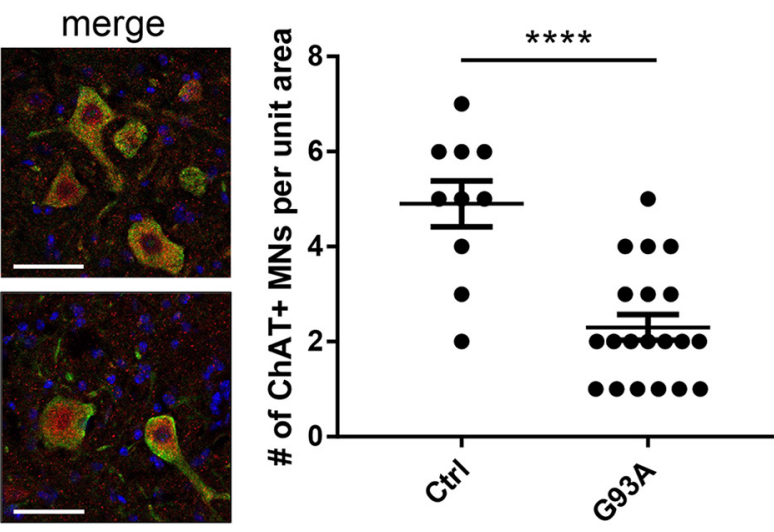

Figure 5. miR-218 levels are maintained in surviving MNs in ALS model mice. $A$, miR-218 levels in ALS spinal MNs are not significantly changed from presymptomatic (70 d) to symptomatic $(140 \mathrm{~d})$ time points in ALS model mice. $n=5 /$ time point. $B$, miR-218 fluorescent signal in ChAT ${ }^{+}$spinal MNs is not changed significantly between littermate control and SOD1 ${ }^{693 \mathrm{~A}} 140 \mathrm{~d}$ mice. $n=$ 46-49 ChAT ${ }^{+}$MNs/group. C, Representative images of miR-218 in situ and ChAT staining in control and SOD1 ${ }^{693 A} 140 \mathrm{~d}$ mouse model spinal cord. Scale bar, $50 \mu \mathrm{m}$. D, Quantification of 10 littermate control and $20 \mathrm{SOD} 1^{\mathrm{G} 93 \mathrm{~A}}$ spinal cord sections. The number of $\mathrm{ChAT}{ }^{+}$spinal MNs per unit area is significantly different between littermate control and SOD1 ${ }^{693 \mathrm{~A}} 140 \mathrm{~d} \mathrm{mice.} \mathrm{Values} \mathrm{are}$ expressed as mean $\pm \operatorname{SEM}(\boldsymbol{A}, \boldsymbol{B}, \boldsymbol{D})$. ${ }^{* * *} p \leq 0.0001$. Student's two-tailed, unpaired $t$ test $(\boldsymbol{A}, \boldsymbol{B}, \boldsymbol{D})$.

proaches indicate that miR-218 depletion in ALS spinal cord tissue is likely due to MN loss because miR-218 levels are mostly maintained within the surviving MNs.

\section{miR-218 increases in ALS model CSF}

To determine whether MN-enriched miRNAs may be a useful marker of MN health, we examined MN miRNAs in CSF, which bathes the brain and spinal cord. We hypothesized that MN miRNAs would be depleted in CSF during MN disease similar to spinal cord tissue. We used ALS SOD $1{ }^{\text {G93A }}$ rats (Howland et al., 2002) for these CSF studies because of the larger volume of CSF obtained from rats compared with mice. Surprisingly, miR-218 was temporally increased in the CSF of ALS model rats compared with nontransgenic littermate controls (Fig. 6A). To ensure that this effect was not simply due to $h S O D 1$ overexpression (Chan et al., 1998), we measured miR-218 levels in CSF from rats overexpressing WT hSOD1 at 90 and $165 \mathrm{~d}$. miR-218 CSF levels were not significantly different in hSOD1 ${ }^{\mathrm{WT}}$ rats compared with nontransgenics at either time point (Fig. 6A). Furthermore, increased expression of miR-218 in ALS rat model CSF is not due to global increases in miRNA expression in CSF because the neuronal miRNAs miR-132 and miR124 were not significantly changed in rat SOD $1{ }^{\text {G93A }}$ CSF compared with nontransgenic controls (Fig. 6B). These data suggest that miR218 levels are increased in CSF during MN disease.

Because miR-218 is highly enriched in MNs compared with other CNS cell types, its increased levels in CSF during MN disease are potentially related to $\mathrm{MN}$ loss or dysfunction. Because
MN loss in ALS model rats is due to expression of mutant $h S O D 1$, we hypothesized that decreasing the levels of the toxic transgene SOD $1{ }^{\mathrm{G} 93 \mathrm{~A}}$ would spare MNs and their function, potentially preventing increased miR-218 levels in the CSF. We used ASOs against SOD1 to specifically lower hSOD1 and prevent the loss of hindlimb grip strength (Smith et al., 2006). We treated ALS SOD1 ${ }^{\text {G93A }}$ rats with hSOD1 ASO or aCSF (the vehicle solution used for delivery of drugs to the CNS). As predicted, hSOD1 mRNA was significantly lowered $(\sim 75 \%)$ in the lumbar spinal cord of these animals (assessed $50 \mathrm{~d}$ after treatment; Fig. 7A) and hindlimb grip strength was preserved (Fig. $7 B$ ), confirming a functional effect of reducing the toxic SOD1 transgene. miR-218 CSF levels were not reduced in scrambled ASO-treated rats (Fig. 7C) but, strikingly, were reduced in the hSOD1 ASO-treated group (Fig. 7D) compared with aCSFtreated littermate controls. However, the CSF levels of neuronal miR-132 and 124 were not affected by SOD1 ASO treatment, demonstrating that miR-218 CSF levels are selectively responsive to $\mathrm{MN}$ function-sparing therapy (Fig. $7 E$ ). Furthermore, hSOD1 mRNA levels correlate well with miR-218 CSF levels, indicating that the increased miR-218 CSF levels are directly responsive to $\mathrm{MN}$ function-sparing therapy and may be a relevant proxy for $\mathrm{MN}$ health during MN disease (Fig. $7 F$ ). Finally, treatment of nontransgenic rats with aCSF and scrambled or hSOD1 ASO does not affect miR-218 CSF levels (Fig. 7G). Together, these data demonstrate that $\mathrm{MN}$-enriched miR-218 may serve as a drug-responsive marker of $\mathrm{MN}$ disease in ALS model rats. 


\section{Relationship between MN loss and extracellular miR-218}

It has been demonstrated previously that tissue-enriched miRNAs are increased in serum after injury to those tissues (Corsten et al., 2010; Zhang et al., 2010). Similarly, we found that a MNenriched miRNA, miR-218, is increased in the CSF of ALS model rats, a MN disease. To determine whether miR-218 is released extracellularly subsequent to $\mathrm{MN}$ loss, we correlated miR-218 CSF levels to the number of spinal MNs and miR-218 levels in spinal cord tissue of ALS model rats. To mark MNs in the anterior horns of the lumbar spinal cord, we used SMI-32 (which is also known as neurofilament heavy). Overall, increased miR-218 CSF levels are highly and significantly correlated with loss of SMI-32 ${ }^{+}$MNs in spinal cord tissue (Fig. 8A). Moreover, the number of SMI-32 ${ }^{+}$MNs and miR-218 levels in the spinal cord are positively correlated, suggesting miR-218 spinal cord levels can be used as a proxy for total number of MNs (Fig. 8B). Although increased miR-218 CSF levels are associated with MN loss, because miR-218 can be measured readily in the CSF of nontransgenic rats, there may be a physiological level of miR-218 release outside of the context of MN disease.

Previous studies suggest that ALS MNs die by necrosis/ necroptosis, which is a form of cell death that involves leakage of cellular components into the extracellular space (Re et al., 2014). Increased miR-218 CSF levels due to MN loss would be consistent with ALS MNs dying by necrosis and subsequently releasing miR-218 and other cellular components. To further investigate whether MN loss leads to miR-218 release, we used Hb9-GFP primary mouse MNs. miR-218 is measureable in the media of these cells, making them a good model with which to study miR218 release. We treated primary MNs with sodium arsenite for $4 \mathrm{~h}$ and sampled the media repeatedly at 0,2 , and $4 \mathrm{~h}$ to probe the release of miR-218 and its relation to cell death. Similar to ALS rat CSF, miR-218 was increased temporally in the media of Hb9GFP MNs treated with sodium arsenite and this increase correlated well with LDH activity, a media marker of cell death (Fig. $9 A, B)$. Therefore, it is likely that the extracellular release of miR218 during $\mathrm{MN}$ disease is at least partially attributed to MN loss. Finally, miR-218 is also present in the media of human iPSCderived MNs and is released in response to injury/death (Fig. $9 C, D)$. These data suggest that miR-218 release is related to MN dysfunction and death and occurs in both animal and human models of MN loss and disease.

\section{Discussion}

This study employed tools to assess in vivo miRNA expression in a cell-type-specific manner to discriminate $\mathrm{MN}$-enriched miRNA expression in CNS tissues. We anticipate that this dataset of MN-enriched miRNAs will facilitate broad insights into MN disease mechanisms, risk factors, and genetics underlying MN vulnerability. Our data also suggest that MN-enriched miRNAs may act functionally in MNs to repress transcription factors important for non-MNs and thus help to define postnatal MN identity. By focusing on MN-enriched miRNA expression in models of $\mathrm{MN}$ disease, we defined a $\mathrm{MN}$-specific and drug-responsive marker in ALS rodents. Finally, this work intersects with a growing field of extracellular release of miRNAs and its physiological and pathological consequences.

In vivo cell-type-specific expression profiling techniques allow high-throughput access to key disease-relevant cell types, yet preserve physiological relevance compared with traditional ex vivo methods such as fluorescence activated cell sorting (FACS) and laser capture and microdissections (LCMs). This in vivo approach is particularly relevant for ALS. MNs have long processes that would be difficult to maintain during tissue dissociation for FACS and dissociation is particularly challenging from adult animals, which are key to profile in models of neurodegenerative disease. There is also the possibility that dissociation itself may induce stress-related changes in the profile. Likewise, LCM is lower throughput and overlapping processes from neighboring cells may contaminate the MN sample (Kummari et al., 2015). We adopted a comparative, systematic approach to define MNenriched miRNA expression relative to other CNS cell types. Inclusion of a pan-neuronal line allowed us to define which miRNAs distinguish MNs specifically from neurons in general, whereas comparison with profiles containing microglia and astrocytes provided key controls and baseline data to facilitate future analyses with understanding the molecular correlates of the well known histological response of these cell types to disease pathology. The ability to define in vivo, cell-type-enriched expression enables broad application of the concept of profiling the cell type most affected by a particular disease to understand disease mechanism and identify markers.

Although this work focused on MN-enriched miRNAs in MN disease, ALS and other neurodegenerative disease processes are non-cell autonomous (Ilieva et al., 2009). Therefore, we also defined miRNAs enriched in astrocytes, microglia, and all other neurons (Fig. 1-1 available at https://doi.org/ 10.1523/JNEUROSCI.3582-16.2017.f1-1) and we expect that this dataset will be broadly informative for ALS and other neurological diseases. For example, there is a growing body of work showing that gliosis and glial dysfunction may precede neuronal loss in many neurodegenerative diseases (Hong et 


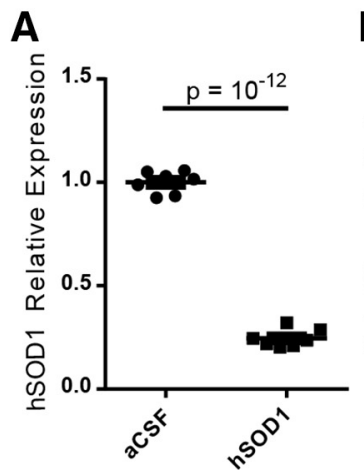

B
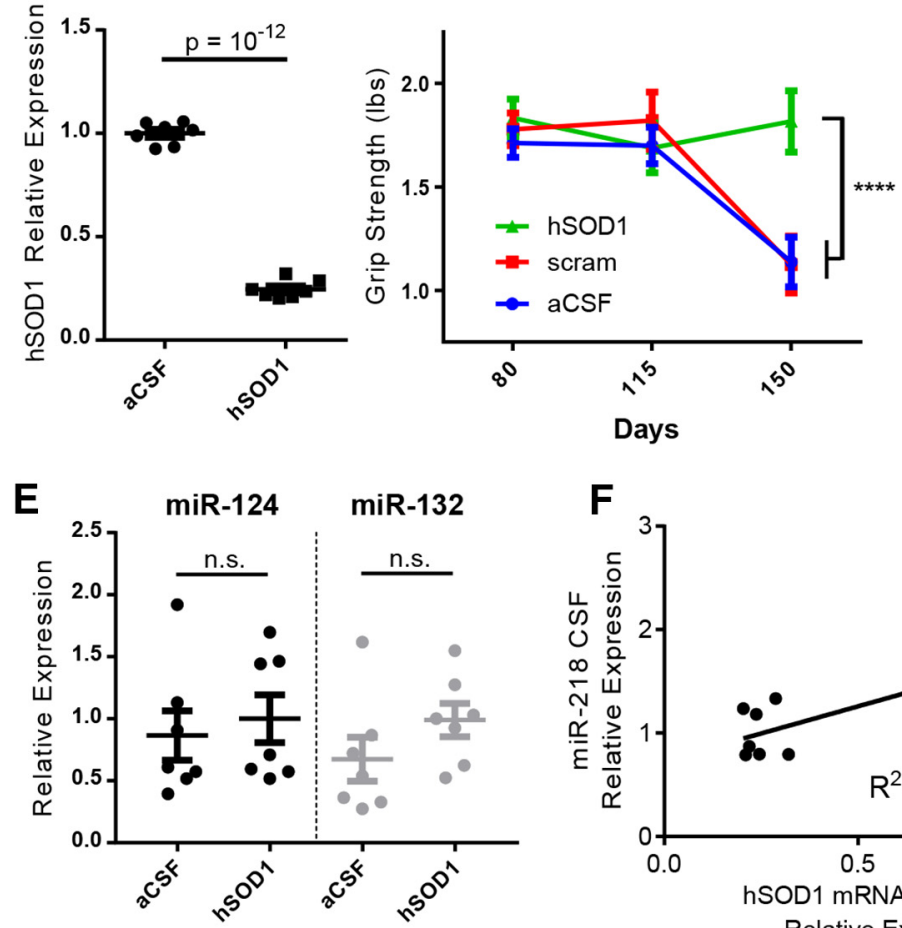

C
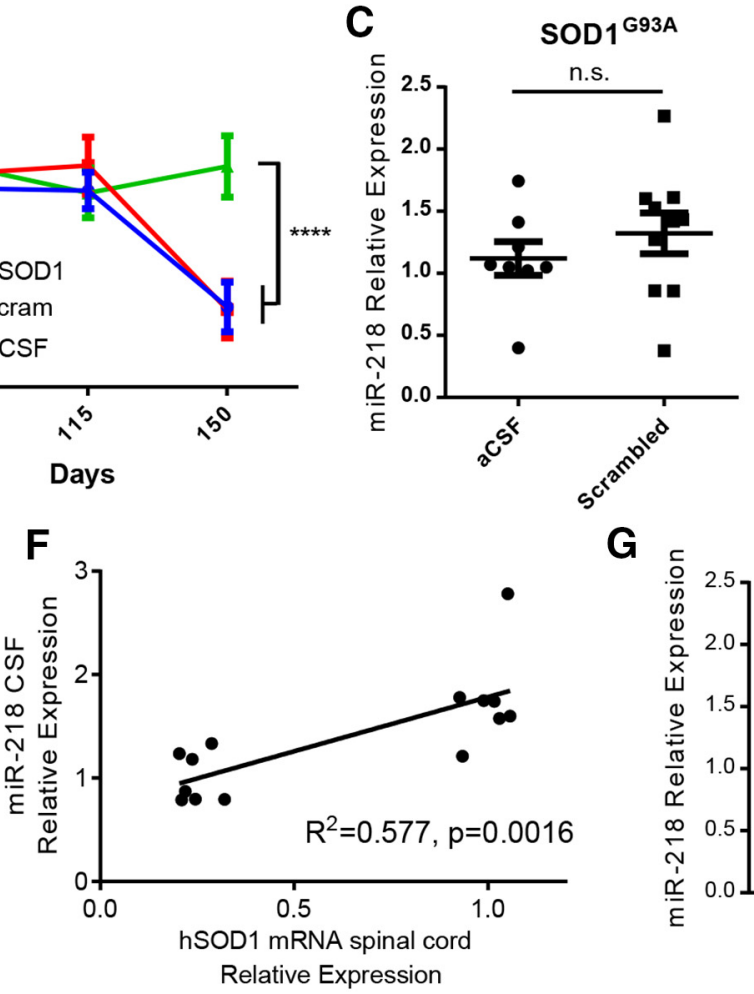

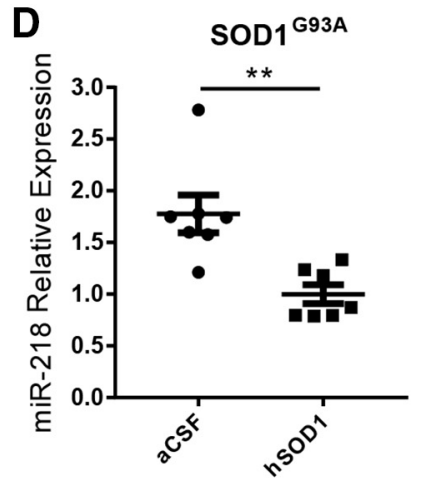

G

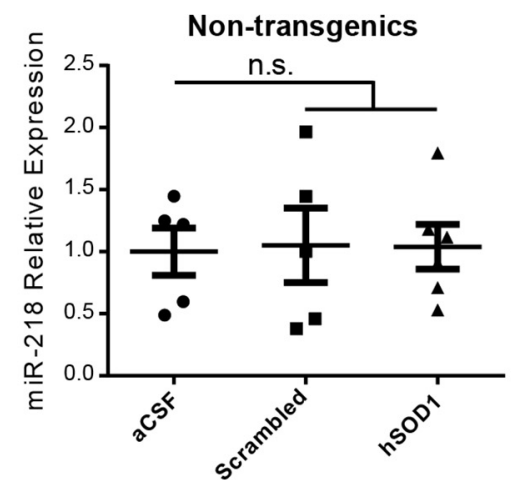

Figure 7. hSOD1 knockdown specifically and effectively preserves MN function and MN-enriched miRNAs are responsive to therapy. A, hSOD1 mRNA knockdown after treatment with hSOD1 ASO. There is an average $75 \%$ reduction in hSOD1 levels in the lumbar spinal cord of SOD $1{ }^{\mathrm{G} 93 \mathrm{~A}}$ rats treated with SOD1 ASO compared with aCSF-treated controls. $n=7 /$ group. $\boldsymbol{B}$, Hindlimb grip strength of aCSF, scrambled ASO, and hSOD1 ASO-treated SOD1 ${ }^{\text {G93A }}$ rats at 80, 115, and $150 \mathrm{~d}$. C, miR-218 CSF levels are not significantly different in aCSF- and scrambled ASO-treated SOD1 ${ }^{\text {G93A }}$ littermates. $n=8-10 . D$, miR-218 in CSF is reduced in rats treated with S0D1-lowering ASO compared with aCSF-treated controls. $n=7 /$ group. These aCSF vs scrambled ASO and aCSF vs hSOD1 ASO treatment cohorts were tested at separate time points. $\boldsymbol{E}$, The neuronal miRNAs miR-132 and miR-124 are not responsive to ALS therapy. $n=7 / g$ roup. $F$, miR-218 CSF levels have a strong and significant correlation with hSOD1 mRNA spinal cord levels. G, miR-218 CSF levels are not changed after treatment with aCSF, scrambled, orhSOD1 ASO in nontransgenic rats. $n=5 / \mathrm{group}$. Values are expressed as mean \pm SEM and are normalized to GAPDH $(\boldsymbol{A})$ or a geometric mean of endogenous miRNA biological fluid controls, miR-103a, miR-24, and miR-191 $(\boldsymbol{C}-\boldsymbol{E}, \boldsymbol{G}) .{ }^{* *} p \leq 0.01,{ }^{* * * *} p \leq 0.0001$, Student's unpaired, two-tailed $t$ test $(\boldsymbol{A}, \boldsymbol{C}, \boldsymbol{D}, \boldsymbol{E})$, one-way ANOVA $(\boldsymbol{G})$, two-way ANOVA $(\boldsymbol{B})$, linear regression analysis $(\boldsymbol{F})$.
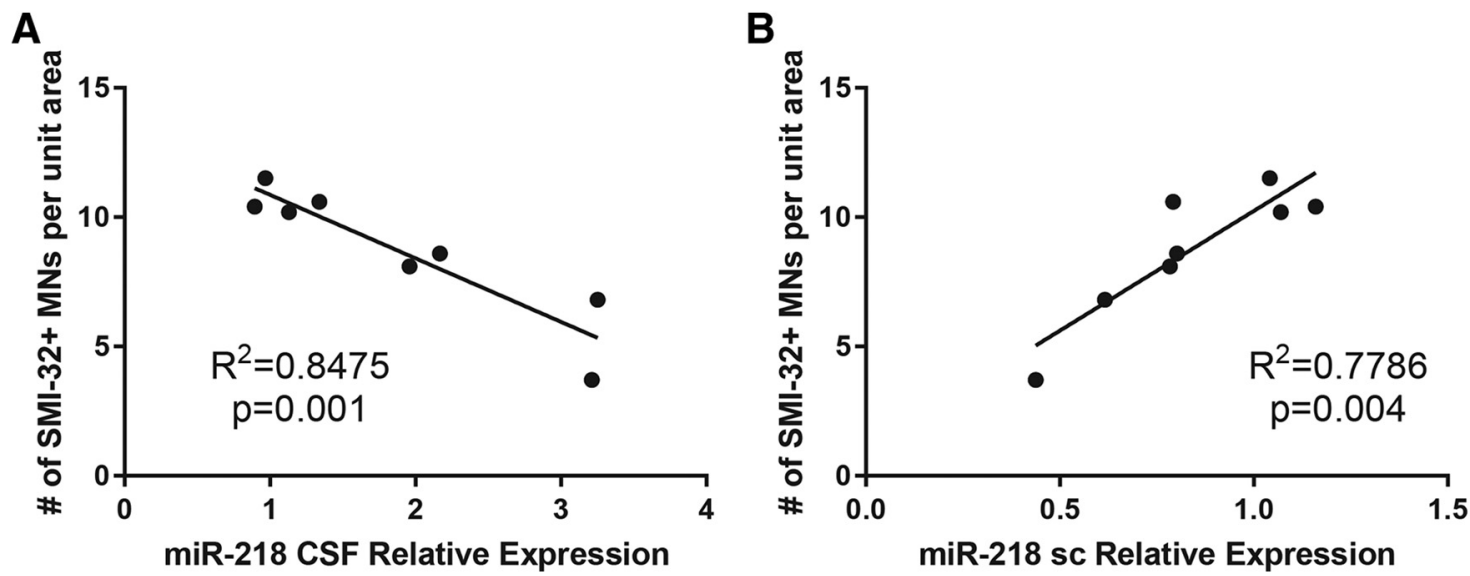

Figure 8. Increased miR-218 CSF levels are correlated with number of remaining SMI- $32^{+}$spinal MNs in ALS model rats. $A$, Number of SMI-32 ${ }^{+}$MNs in the lumbar spinal cord of ALS rats is negatively and highly correlated with their corresponding miR-218CSF levels. B, Number of SMI- $32^{+}{ }^{M N s}$ is positively and highly correlated with corresponding miR-218 levels in lumbar spinal cord tissue. Linear regression analysis was used.

al., 2016; Clayton et al., 2017), so understanding dysregulation of glial-enriched miRNAs may also lead to novel biomarkers and therapies.

Furthermore, the dataset generated here could identify additional novel miRNAs involved in cell fate specification, particularly those exhibiting enriched expression in a single CNS cell type. For example, recent work indicates that miR-218 is en- riched in MNs of other organisms (Kapsimali et al., 2007; Punnamoottil et al., 2015), may be important for MN differentiation (Thiebes et al., 2015), and is indispensable for embryonic MNs (Amin et al., 2015). Our work demonstrates that miR-218 retains its specificity in adult MNs and also identifies other MN miRNAs that may be equally important. By comparing the actively translated mRNAs in MNs with all other spinal neurons, we demon- 
B

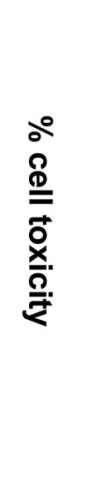

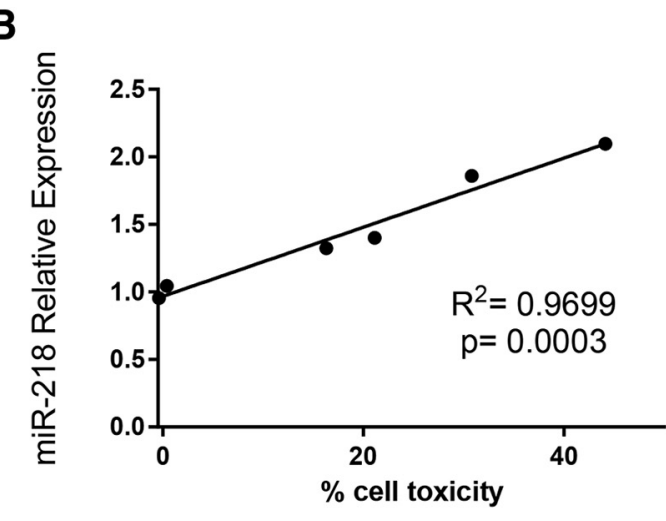

D

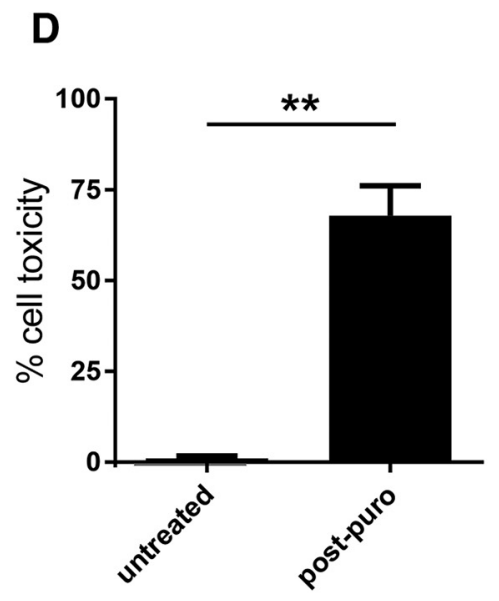

Figure 9. Extracellular miR-218 levels are increased subsequent to $M N$ injury or death. $A$, miR-218 levels and LDH levels (shown as percentage cell toxicity) are temporally increased in the media of primary Hb9-GFP MNs treated with $1 \mathrm{~mm}$ sodium arsenite. $n=2 /$ group. $\boldsymbol{B}$, miR-218 media levels are strongly correlated with LDH activity, a marker of cell death. $n=2 / \mathrm{group}$ with 3 technical replicates per $n$. C, miR-218 is increased in the media of iPSC-derived MNs after puromycin treatment. $n=3$. D, LDH activity (shown as percentage cell toxicity) is increased after puromycin treatment. $n=3$ with 3 technical replicates per $n$. Values are expressed at mean \pm SEM and are normalized to media volume $(\boldsymbol{A}, \boldsymbol{C}){ }^{*} p \leq 0.05$, ${ }^{* *} p \leq 0.01$, linear regression analysis $(\boldsymbol{B})$, Student's unpaired, two-tailed $t$ test $(\boldsymbol{C}, \boldsymbol{D})$.

strated that mRNAs containing binding sites for MN-enriched miRNAs appear relatively repressed in the MNs. Because mRNA and miRNA profiling was performed postnatally, these data suggest that MN-enriched miRNAs continue to define MN identity after development. In the future, it would be interesting to investigate how the downregulation of individual targets of $\mathrm{MN}$ enriched miRNAs maintains MN identity. Moreover, this same approach can be applied to miRNAs enriched in glial cell types as well as miRNAs that are dysregulated in disease.

Our data also demonstrate that miR-218 is a marker of MN loss and/or injury in ALS rat model CSF. Mouse miR-218 exists at two different genomic loci within the introns of SLIT2 and SLIT3 (miR-218-1, chr5: 48223942-48224051; miR-218-2, chr11:35616816-35616925). Recently, miR-218 was shown to be $\mathrm{MN}$-enriched in mouse embryos and to be critical for MN function. Genetic deletion of both miR-218 loci in mice resulted in embryonic inability to form functional neuromuscular junctions and, ultimately, MN degeneration (Amin et al., 2015). Although the loss of miR-218 developmentally causes MN degeneration, we found that miR-218 spinal cord levels are depleted due to MN loss, not downregulation, and mir-218 levels are maintained in the MNs that survive in ALS (Fig. $5 A-D$ ). These data indicate that miR-218 loss from spinal cord tissue is likely subsequent to MN loss in ALS and thus may not be a cause of MN degeneration in ALS rodent models. However, it remains possible that miR-218 could be downregulated acutely in each MN shortly before death. Future studies involving in vitro cultures could be used to monitor miR-218 levels dynamically in individual ALS MNs antecedent to cell death. Regardless, our work corroborates previous studies demonstrating the MN specificity of miR-218, highlights the importance of miR-218 in adults, and clarifies its relation to MN health and disease in ALS models.

Currently, the mechanism underlying increased miR-218 in ALS rat CSF is unknown. Our data are consistent with miR-218 being released extracellularly subsequent to MN loss (Figs. 8A, 9). However, it is also possible that some release of miR-218 into the CSF may reflect an additional active response operating independently of MN loss because some miR-218 is released into the CSF before significant MN loss in ALS model rats (Fig. 8A). Although clearance of proteins and other molecules into CSF can result from normal physiological processes, there is also increasing evidence that release into the CSF can be pathological as well (Aluise et al., 2008; Su et al., 2014). Future studies will help to delineate whether the increased levels of miR-218 in ALS rat CSF is solely due to MN loss and subsequent clearance or to an active signal or homeostatic attempt from diseased MNs. Understanding whether miR-218 is also changed in spinal muscular atrophy, spinal cord injury, or other $\mathrm{MN}$ diseases may also provide insights into the miR-218 CSF signal.

Despite many efforts, there are a limited number of reliable biomarkers for ALS. One of the most promising biomarkers thus far is neurofilament, a marker of neuroaxonal degeneration. Both 
phosphorylated neurofilament heavy and neurofilament light have been shown to be increased in CSF and serum of ALS patients compared with neurological disease controls (Rosengren et al., 1996; Lu et al., 2015; Oeckl et al., 2016). Furthermore, neurofilament light is a good prognostic marker for ALS; higher CSF levels are associated with shorter survival (Weydt et al., 2016; Gaiani et al., 2017). In addition, repeat expansions in C9orf72 $\left(\mathrm{C}^{+}\right)$are attributed to $>40 \%$ of ALS cases and dipeptide repeat proteins (DPRs) produced from RAN translation of the repeats can be measured in the CSF of C9 ${ }^{+}$ALS patients (Su et al., 2014). It was demonstrated recently that these DPRs can serve as pharmacodynamic biomarkers for $\mathrm{C}^{+}{ }^{+}$ALS patients (Gendron et al., 2017). However, none of these markers has been shown to change longitudinally within individual patients as disease progresses.

We are optimistic that miR-218 could be used as a marker of human ALS. However, at the present time using available methods, miR-218, although quantifiable in some samples, is below the limit of detection in others and thus a valid comparison between ALS and controls is not yet achievable. Despite these limitations, we remain enthusiastic that miR-218 will be measured reliably in human CSF. In ALS model rats, miR-218 CSF levels correlate well with the number of remaining spinal MNs, do not appear to reach a plateau, and are responsive to $\mathrm{MN}$-sparing therapy. If miR-218 levels could be detected in humans, then CSF miR-218 could be used to assess a drug's ability to affect MNs, thus potentially selecting a more promising candidate for a longer trial. Furthermore, because miR-218 is increased temporally during ALS rat model disease progression, longitudinal assessment of miR-218 in clinical trials could indicate whether MN loss is ongoing or if it has been stabilized by MN-sparing therapy.

Presently, miR-218 is measureable in the media of human iPSC-derived MNs (Fig. 9C). There has been an increased interest in using iPSC models to generate preclinical data, especially for ALS (Answer ALS, clinical trial NCT02574390). The media levels of miR-218 may be a useful proxy for MN health in these studies as well because RNA can be quantified from $<100 \mu$ l of medium. Furthermore, because of the MN specificity of miR-218, this may allow for monitoring of $\mathrm{MN}$ toxicity specifically when cultures contain a variety of cell types.

This study has identified a MN-specific, drug-responsive marker of an ALS rodent model of MN disease. Our approach highlights a pipeline for hypothesis-driven development of specific miRNA markers of particular cell types and a means of predicting their functionality on mRNA expression in relevant cell types. Although miR-218 needs further validation, especially in human ALS CSF, it has the potential to become a MN-specific, drug-responsive marker in humans, with important implications for the design and assessment of efficacy of MN disease therapies.

\section{References}

Aluise CD, Sowell RA, Butterfield DA (2008) Peptides and proteins in plasma and cerebrospinal fluid as biomarkers for the prediction, diagnosis, and monitoring of therapeutic efficacy of Alzheimer's disease. Biochim Biophys Acta 1782:549-558. CrossRef Medline

Amin ND, Bai G, Klug JR, Bonanomi D, Pankratz MT, Gifford WD, Hinckley CA, Sternfeld MJ, Driscoll SP, Dominguez B, Lee KF, Jin X, Pfaff SL (2015) Loss of motoneuron-specific microRNA-218 causes systemic neuromuscular failure. Science 350:1525-1529. CrossRef Medline

Andreasen D, Fog JU, Biggs W, Salomon J, Dahslveen IK, Baker A, Mouritzen $P$ (2010) Improved microRNA quantification in total RNA from clinical samples. Methods 50:S6-S9. CrossRef Medline

Ardekani AM, Naeini MM (2010) The role of microRNAs in human diseases. Avicenna J Med Biotechnol 2:161-179. Medline

Bajenaru ML, Zhu Y, Hedrick NM, Donahoe J, Parada LF, Gutmann DH (2002) Astrocyte-specific inactivation of the neurofibromatosis 1 gene
(NF1) is insufficient for astrocytoma formation. Mol Cell Biol 22:51005113. CrossRef Medline

Boillée S, Yamanaka K, Lobsiger CS, Copeland NG, Jenkins NA, Kassiotis G, Kollias G, Cleveland DW (2006) Onset and progression in inherited ALS determined by motor neurons and microglia. Science 312:1389_ 1392. CrossRef Medline

Boulting GL, Kiskinis E, Croft GF, Amoroso MW, Oakley DH, Wainger BJ, Williams DJ, Kahler DJ, Yamaki M, Davidow L, Rodolfa CT, Dimos JT, Mikkilineni S, MacDermott AB, Woolf CJ, Henderson CE, Wichterle H, Eggan K (2011) A functionally characterized test set of human induced pluripotent stem cells. Nat Biotechnol 29:279-286. CrossRef Medline

Butovsky O, Jedrychowski MP, Cialic R, Krasemann S, Murugaiyan G, Fanek Z, Greco DJ, Wu PM, Doykan CE, Kiner O, Lawson RJ, Frosch MP, Pochet N, Fatimy RE, Krichevsky AM, Gygi SP, Lassmann H, Berry J, Cudkowicz ME, Weiner HL (2014) Targeting miR-155 restores abnormal microglia and attenuates disease in SOD1 mice. Ann Neurol 77:7599. CrossRef Medline

Chan PH, Kawase M, Murakami K, Chen SF, Li Y, Calagui B, Reola L, Carlson E, Epstein CJ (1998) Overexpression of SOD1 in transgenic rats protects vulnerable neurons against ischemic damage after global cerebral ischemia and reperfusion. J Neurosci 18:8292-8299. Medline

Chekulaeva M, Filipowicz W (2009) Mechanisms of miRNA-mediated post-transcriptional regulation in animal cells. Curr Opin Cell Biol 21: 452-460. CrossRef Medline

Chen JF, Mandel EM, Thomson JM, Wu Q, Callis TE, Hammond SM, Conlon FL, Wang DZ (2006) The role of microRNA-1 and microRNA-133 in skeletal muscle proliferation and differentiation. Nat Genet 38:228-233. CrossRef Medline

Chen X, et al. (2008) Characterization of microRNAs in serum: a novel class of biomarkers for diagnosis of cancer and other diseases. Cell Res 18:997-1006. CrossRef Medline

Chi SW, Zang JB, Mele A, Darnell RB (2009) Argonaute HITS-CLIP decodes microRNA-mRNA interaction maps. Nature 460:479-486. CrossRef Medline

Clausen BE, Burkhardt C, Reith W, Renkawitz R, Förster I (1999) Conditional gene targeting in macrophages and granulocytes using LysMcre mice. Transgenic Res 8:265-277. CrossRef Medline

Clayton EL, et al. (2017) Early microgliosis precedes neuronal loss and behavioural impairment in mice with a frontotemporal dementia-causing CHMP2B mutation. Hum Mol Genet. In press.

Corsten MF, Dennert R, Jochems S, Kuznetsova T, Devaux Y, Hofstra L, Wagner DR, Staessen JA, Heymans S, Schroen B (2010) Circulating MicroRNA-208b and MicroRNA-499 reflect myocardial damage in cardiovascular disease. Circ Cardiovasc Genet 3:499-506. CrossRef Medline

Dasen JS, De Camilli A, Wang B, Tucker PW, Jessell TM (2008) Hox repertoires for motor neuron diversity and connectivity gated by a single accessory factor, FoxP1. Cell 134:304-316. CrossRef Medline

de Faria O Jr, Cui QL, Bin JM, Bull SJ, Kennedy TE, Bar-Or A, Antel JP, Colman DR, Dhaunchak AS (2012) Regulation of miRNA 219 and miRNA clusters 338 and 17-92 in oligodendrocytes. Front Genet 3:46. CrossRef Medline

Donnelly CJ, et al. (2013) RNA toxicity from the ALS/FTD C9ORF72 expansion is mitigated by antisense intervention. Neuron 80:415-428. CrossRef Medline

Dougherty JD, Schmidt EF, Nakajima M, Heintz N (2010) Analytical approaches to RNA profiling data for the identification of genes enriched in specific cells. Nucleic Acids Res 38:4218-4230. CrossRef Medline

Faust N, Varas F, Kelly LM, Heck S, Graf T (2000) Insertion of enhanced green fluorescent protein into the lysozyme gene creates mice with green fluorescent granulocytes and macrophages. Blood 96:719-726. Medline

Gaiani A, Martinelli I, Bello L, Querin G, Puthenparampil M, Ruggero S, Toffanin E, Cagnin A, Briani C, Pegoraro E, Soraru G (2017) Diagnostic and prognostic biomarkers in amyotrophic lateral sclerosis: neurofilament light chain levels in definite subtypes of disease. JAMA Neurol. In press.

Gendron TF, et al. (2017) Poly(GP) proteins are a useful pharmacodynamic marker for C9ORF72-associated amyotrophic lateral sclerosis. Sci Transl Med 9: pii: eaai7866. CrossRef Medline

Gregory RI, Chendrimada TP, Cooch N, Shiekhattar R (2005) Human RISC couples microRNA biogenesis and posttranscriptional gene silencing. Cell 123:631-640. CrossRef Medline

Ha M, Kim VN (2014) Regulation of microRNA biogenesis. Nat Rev Mol Cell Biol 15:509-524. CrossRef Medline 
Hammond SM (2005) Dicing and slicing: the core machinery of the RNA interference pathway. FEBS Lett 579:5822-5829. CrossRef Medline

Hammond SM, Boettcher S, Caudy AA, Kobayashi R, Hannon GJ (2001) Argonaute2, a link between genetic and biochemical analyses of RNAi. Science 293:1146-1150. CrossRef Medline

He M, Liu Y, Wang X, Zhang MQ, Hannon GJ, Huang ZJ (2012) Cell-typebased analysis of microRNA profiles in the mouse brain. Neuron 73:3548. CrossRef Medline

Hilfiker S, Pieribone VA, Czernik AJ, Kao HT, Augustine GJ, Greengard P (1999) Synapsins as regulators of neurotransmitter release. Philos Trans R Soc Lond B Biol Sci 354:269-279. CrossRef Medline

Hong S, Beja-Glasser VF, Nfonoyim BM, Frouin A, Li S, Ramakrishnan S, Merry KM, Shi Q, Rosenthal A, Barres BA, Lemere CA, Selkoe DJ, Stevens B (2016) Complement and microglia mediate early synapse loss in Alzheimer mouse models. Science 352:712-716. CrossRef Medline

Howland DS, Liu J, She Y, Goad B, Maragakis NJ, Kim B, Erickson J, Kulik J, DeVito L, Psaltis G, DeGennaro LJ, Cleveland DW, Rothstein JD (2002) Focal loss of the glutamate transporter EAAT2 in a transgenic rat model of SOD1 mutant-mediated amyotrophic lateral sclerosis (ALS). Proc Natl Acad Sci U S A 99:1604-1609. CrossRef Medline

Huang da W, Sherman BT, Lempicki RA (2009a) Bioinformatics enrichment tools: paths toward the comprehensive functional analysis of large gene lists. Nucleic Acids Res 37:1-13. CrossRef Medline

Huang da W, Sherman BT, Lempicki RA (2009b) Systematic and integrative analysis of large gene lists using DAVID bioinformatics resources. Nat Protoc 4:44-57. CrossRef Medline

Ilieva H, Polymenidou M, Cleveland DW (2009) Non-cell autonomous toxicity in neurodegenerative disorders: ALS and beyond. J Cell Biol 187: 761-772. CrossRef Medline

Kapsimali M, Kloosterman WP, de Bruijn E, Rosa F, Plasterk RH, Wilson SW (2007) MicroRNAs show a wide diversity of expression profiles in the developing and mature central nervous system. Genome Biol 8:R173. CrossRef Medline

Klipper-Aurbach Y, Wasserman M, Braunspiegel-Weintrob N, Borstein D, Peleg S, Assa S, Karp M, Benjamini Y, Hochberg Y, Laron Z (1995) Mathematical formulae for the prediction of the residual beta cell function during the first two years of disease in children and adolescents with insulin-dependent diabetes mellitus. Med Hypotheses 45:486-490. CrossRef Medline

Koval ED, Shaner C, Zhang P, du Maine X, Fischer K, Tay J, Chau BN, Wu GF, Miller TM (2013) Method for widespread microRNA-155 inhibition prolongs survival in ALS-model mice. Hum Mol Genet 22:4127-4135. CrossRef Medline

Kummari E, Guo-Ross SX, Eells JB (2015) Laser capture microdissection-a demonstration of the isolation of individual dopamine neurons and the entire ventral tegmental area. J Vis Exp e52336. CrossRef Medline

Lappe-Siefke C, Goebbels S, Gravel M, Nicksch E, Lee J, Braun PE, Griffiths IR, Nave KA (2003) Disruption of Cnp1 uncouples oligodendroglial functions in axonal support and myelination. Nat Genet 33:366-374. CrossRef Medline

Lu CH, Macdonald-Wallis C, Gray E, Pearce N, Petzold A, Norgren N, Giovannoni G, Fratta P, Sidle K, Fish M, Orrell R, Howard R, Talbot K, Greensmith L, Kuhle J, Turner MR, Malaspina A (2015) Neurofilament light chain: a prognostic biomarker in amyotrophic lateral sclerosis. Neurology 84:2247-2257. CrossRef Medline

McCloy RA, Rogers S, Caldon CE, Lorca T, Castro A, Burgess A (2014) Partial inhibition of Cdk1 in G 2 phase overrides the SAC and decouples mitotic events. Cell Cycle 13:1400-1412. CrossRef Medline

O'Connell RM, Rao DS, Chaudhuri AA, Baltimore D (2010) Physiological and pathological roles for microRNAs in the immune system. Nat Rev Immunol 10:111-122. CrossRef Medline

Oeckl P et al. (2016) Multicenter validation of CSF neurofilaments as diagnostic biomarkers for ALS. Amyotroph Lateral Scler Frontotemporal Degener 17:404-413. CrossRef Medline

Pasinelli P, Brown RH (2006) Molecular biology of amyotrophic lateral sclerosis: insights from genetics. Nat Rev Neurosci 7:710-723. CrossRef Medline

Peltier HJ, Latham GJ (2008) Normalization of microRNA expression levels in quantitative RT-PCR assays: identification of suitable reference RNA targets in normal and cancerous human solid tissues. RNA 14:844-852. CrossRef Medline

Pillai A, Mansouri A, Behringer R, Westphal H, Goulding M (2007) Lhx1 and
Lhx5 maintain the inhibitory-neurotransmitter status of interneurons in the dorsal spinal cord. Development 134:357-366. CrossRef Medline

Punnamoottil B, Rinkwitz S, Giacomotto J, Svahn AJ, Becker TS (2015) Motor neuron-expressed microRNAs 218 and their enhancers are nested within introns of Slit2/3 genes. Genesis 53:321-328. CrossRef Medline

Re DB, Le Verche V, Yu C, Amoroso MW, Politi KA, Phani S, Ikiz B, Hoffmann L, Koolen M, Nagata T, Papadimitriou D, Nagy P, Mitsumoto H, Kariya S, Wichterle H, Henderson CE, Przedborski S (2014) Necroptosis drives motor neuron death in models of both sporadic and familial ALS. Neuron 81:1001-1008. CrossRef Medline

Risso D, Massa MS, Chiogna M, Romualdi C (2009) A modified LOESS normalization applied to microRNA arrays: a comparative evaluation. Bioinformatics 25:2685-2691. CrossRef Medline

Rosengren LE, Karlsson JE, Karlsson JO, Persson LI, Wikkelsø C (1996) Patients with amyotrophic lateral sclerosis and other neurodegenerative diseases have increased levels of neurofilament protein in CSF. J Neurochem 67:2013-2018. Medline

Rothstein JD (2009) Current hypotheses for the underlying biology of amyotrophic lateral sclerosis. Ann Neurol 65:S3-S9. CrossRef Medline

Rotolo T, Smallwood PM, Williams J, Nathans J (2008) Genetically-directed, cell type-specific sparse labeling for the analysis of neuronal morphology. PLoS One 3:e4099. CrossRef Medline

Sayed D, Abdellatif M (2011) MicroRNAs in development and disease. Physiol Rev 91:827-887. CrossRef Medline

Selbach M, Schwanhäusser B, Thierfelder N, Fang Z, Khanin R, Rajewsky N (2008) Widespread changes in protein synthesis induced by microRNAs. Nature 455:58-63. CrossRef Medline

Smith RA, Miller TM, Yamanaka K, Monia BP, Condon TP, Hung G, Lobsiger CS, Ward CM, McAlonis-Downes M, Wei H, Wancewicz EV, Bennett CF, Cleveland DW (2006) Antisense oligonucleotide therapy for neurodegenerative disease. J Clin Invest 116:2290-2296. CrossRef Medline

Smyth GK (2004) Linear models and empirical bayes methods for assessing differential expression in microarray experiments. Stat Appl Genet Mol Biol 3: Article3. Medline

Su Z, et al. (2014) Discovery of a biomarker and lead small molecules to target r(GGGGCC)-associated defects in c9FTD/ALS. Neuron 83:10431050. CrossRef Medline

Thiebes KP, Nam H, Cambronne XA, Shen R, Glasgow SM, Cho HH, Kwon JS, Goodman RH, Lee JW, Lee S, Lee SK (2015) miR-218 is essential to establish motor neuron fate as a downstream effector of Isl1-Lhx3. Nat Commun 6:7718. CrossRef Medline

Wang L, Marquardt T (2012) Direct live monitoring of heterotypic axonaxon interactions in vitro. Nat Protoc 7:351-363. CrossRef Medline

Weydt P, Oeckl P, Huss A, Müller K, Volk AE, Kuhle J, Knehr A, Andersen PM, Prudlo J, Steinacker P, Weishaupt JH, Ludolph AC, Otto M (2016) Neurofilament levels as biomarkers in asymptomatic and symptomatic familial amyotrophic lateral sclerosis. Ann Neurol 79:152-158. CrossRef Medline

Wong N, Wang X (2015) miRDB: an online resource for microRNA target prediction and functional annotations. Nucleic Acids Res 43:D146D152. CrossRef Medline

Wooley CM, Sher RB, Kale A, Frankel WN, Cox GA, Seburn KL (2005) Gait analysis detects early changes in transgenic SOD1(G93A) mice. Muscle Nerve 32:43-50. CrossRef Medline

Xu X, Wells AB, O'Brien DR, Nehorai A, Dougherty JD (2014) Cell typespecific expression analysis to identify putative cellular mechanisms for neurogenetic disorders. J Neurosci 34:1420-1431. CrossRef Medline

Yamanaka K, Chun SJ, Boillée S, Fujimori-Tonou N, Yamashita H, Gutmann DH, Takahashi R, Misawa H, Cleveland DW (2008) Astrocytes as determinants of disease progression in inherited amyotrophic lateral sclerosis. Nat Neurosci 11:251-253. CrossRef Medline

Zetterström P, Graffmo KS, Andersen PM, Brännström T, Marklund SL (2011) Proteins that bind to misfolded mutant superoxide dismutase-1 in spinal cords from transgenic amyotrophic lateral sclerosis (ALS) model mice. J Biol Chem 286:20130-20136. CrossRef Medline

Zhang Y, Jia Y, Zheng R, Guo Y, Wang Y, Guo H, Fei M, Sun S (2010) Plasma microRNA-122 as a biomarker for viral-, alcohol-, and chemicalrelated hepatic diseases. Clin Chem 56:1830-1838. CrossRef Medline

Zhao X, He X, Han X, Yu Y, Ye F, Chen Y, Hoang T, Xu X, Mi QS, Xin M, Wang F, Appel B, Lu QR (2010) MicroRNA-mediated control of oligodendrocyte differentiation. Neuron 65:612-626. CrossRef Medline 